\title{
Type 2 diabetes and reduced exercise tolerance: a review of the literature through an integrated physiology approach
}

\author{
Lorenzo Nesti ${ }^{1} 2^{*}\left(10\right.$, Nicola Riccardo Pugliese ${ }^{2}$, Paolo Sciuto ${ }^{1}$ and Andrea Natali ${ }^{1}$
}

\begin{abstract}
The association between type 2 diabetes mellitus (T2DM) and heart failure (HF) is well established. Early in the course of the diabetic disease, some degree of impaired exercise capacity (a powerful marker of health status with prognostic value) can be frequently highlighted in otherwise asymptomatic T2DM subjects. However, the literature is quite heterogeneous, and the underlying pathophysiologic mechanisms are far from clear. Imaging-cardiopulmonary exercise testing (CPET) is a non-invasive, provocative test providing a multi-variable assessment of pulmonary, cardiovascular, muscular, and cellular oxidative systems during exercise, capable of offering unique integrated pathophysiological information. With this review we aimed at defying the cardiorespiratory alterations revealed through imaging-CPET that appear specific of T2DM subjects without overt cardiovascular or pulmonary disease. In synthesis, there is compelling evidence indicating a reduction of peak workload, peak oxygen assumption, oxygen pulse, as well as ventilatory efficiency. On the contrary, evidence remains inconclusive about reduced peripheral oxygen extraction, impaired heart rate adjustment, and lower anaerobic threshold, compared to non-diabetic subjects. Based on the multiparametric evaluation provided by imaging-CPET, a dissection and a hierarchy of the underlying mechanisms can be obtained. Here we propose four possible integrated pathophysiological mechanisms, namely myocardiogenic, myogenic, vasculogenic and neurogenic. While each hypothesis alone can potentially explain the majority of the CPET alterations observed, seemingly different combinations exist in any given subject. Finally, a discussion on the effects -and on the physiological mechanisms-of physical activity and exercise training on oxygen uptake in T2DM subjects is also offered. The understanding of the early alterations in the cardiopulmonary response that are specific of T2DM would allow the early identification of those at a higher risk of developing HF and possibly help to understand the pathophysiological link between T2DM and HF.
\end{abstract}

Keywords: Type 2 diabetes mellitus, Cardiopulmonary exercise test, Exercise physiology, Exercise tolerance, Physical exercise, Exercise training, Aerobic capacity, Diabetic complications, Diabetic cardiomyopathy, Diabetic lung, Autonomic dysfunction, Diabetic myopathy

\section{Introduction}

Despite the substantial advances in the clinical management of both diabetes and cardiovascular diseases throughout the world, coronary artery disease and heart

\footnotetext{
*Correspondence: Iorenzonesti90@gmail.com

${ }^{2}$ Cardiopulmonary Test Lab, Department of Clinical and Experimental Medicine, University of Pisa, Via Savi 10, 56126 Pisa, Italy

Full list of author information is available at the end of the article
}

failure (HF) remain the leading causes of the shorter life expectancy observed in subjects with type 2 diabetes mellitus (T2DM) [1]. A reduced exercise capacity, expressed either by reduced achieved peak workload or peak oxygen uptake, is a powerful marker of impaired global health status as well as the hallmark of HF [2]. Indeed, reduced peak oxygen uptake bears a solid negative prognostic value both in the general population [3] and in subjects with, or at high risk of, cardiovascular 
diseases [4]. Asymptomatic T2DM subjects show both a reduced exercise tolerance [5] and an excess risk of developing HF, which are not entirely explained by known cardiovascular risk factors or coronary heart disease. Thus, an early diabetes-related cardiopulmonary impairment has been postulated [1].

Cardiopulmonary exercise test (CPET), by adding ventilation and gas exchange measurement to electrocardiography during a symptom-limited progressive exercise test, is a unique non-invasive protocol providing a multivariable assessment of pulmonary, cardiovascular and muscular function during exercise. The addition of echocardiographic monitoring ("imaging-CPET") can provide further information on the different aspects of cardiac function during exercise and their impact on effort intolerance, mainly used in HF patients [6]. In Table 1 are shown the variables directly measured during the test (primary) and their software modelling (secondary variables), divided according to the systems and organ functions that each of them can assess. The understanding of the early alterations in the cardiopulmonary response that are specific of T2DM subjects would allow the identification of those at a higher risk of developing HF and could orientate the therapeutic strategies as well. Unfortunately, despite the extensive literature available, which alterations are responsible for the reduced exercise tolerance in asymptomatic T2DM subjects without overt cardiovascular complications is still unclear and remains matter of debate.

With this review, by adopting an integrated physiology approach, we will try to highlight the cardiorespiratory alterations that are specific of non-complicated diabetes and discuss both their clinical relevance and, when possible, the underlying pathophysiology.

\section{Exercise capacity in type 2 diabetes and its clinical relevance}

Several studies have evaluated the cardiopulmonary performance in response to physical exercise in T2DMM subjects consistently observing, with respect to normal subjects, a reduced maximal aerobic capacity measured either in metabolic equivalents (METs) or in peak oxygen uptake $\left(\mathrm{VO}_{2 \text { peak }}\right)$ [7-23]. This defect can be quantitatively appreciated from well-matched casecontrols studies in subjects with T2DM and no clinically evident cardiovascular disease or overt diabetic complications, consistently appearing as a $20-30 \%$ reduction in $\mathrm{VO}_{2 \text { peak }}$ in both adults $[18,24,25]$ and adolescents $[26,27]$. The determinants of the reduced aerobic capacity can be deduced from large cohort studies. In the LOOKAHEAD trial [5] (5783 overweight/obese subjects with $\mathrm{T} 2 \mathrm{DM})$ the major predictors were age, body mass index (BMI), female gender, non-white ethnicity, diabetes duration, insulin use and systolic blood pressure. On the contrary, one recent study found no differences in $\mathrm{VO}_{2 \text { peak }}$ in well-controlled, relatively young T2DM subjects with a disease duration of less than 5 years and without clinical complications or comorbidities compared to carefully matched subjects without diabetes [28]. However, a reduced $\mathrm{VO}_{2} /$ workload slope during graded exercise was observed in T2DM women with similar characteristics [18]. These observations suggest that whilst early, well-controlled T2DM may not show a significant reduction in maximal aerobic capacity, the earliest diabetes-related defect could be highlighted by a slight reduction in the efficiency with which oxygen is converted in external work. Unfortunately, this elegant analysis was not performed in other studies.

Table 1 Variables evaluated during cardiopulmonary examination grouped by their physiological value

\begin{tabular}{|c|c|c|}
\hline Physiological mechanism & Imaging-CPET primary variables & CPET secondary variables \\
\hline Whole body & $\mathrm{VO}_{2}$, work & $\mathrm{VO}_{2} \%$ \\
\hline Cardiovascular system & $\mathrm{HR}, \mathrm{BP}$ & $\mathrm{VO}_{2} / \mathrm{HR}$ \\
\hline Cardiac electric activity & ECG morphology and rythm & $\begin{array}{l}\text { Chronotropic insufficiency, } \\
\text { impaired heart rate } \\
\text { recovery }\end{array}$ \\
\hline Ventilation & $V E_{,} V_{T}$ & VENCO ${ }_{2}$, VENO ${ }_{2}$ \\
\hline Gas exchange & $\mathrm{SpO}_{2}, \mathrm{PETCO}_{2}, \mathrm{PETO}_{2}$ & AT \\
\hline Skeletal muscle & Borg scale & $\Delta(\mathrm{a}-\mathrm{v}) \mathrm{O}_{2}, \mathrm{AT}$ \\
\hline Metabolism & RER & AT \\
\hline Systolic function & LVEF, S', TAPSE & Systolic reserve \\
\hline Diastolic function & E/A, E/e', DT & Diastolic reserve \\
\hline
\end{tabular}

We indicated "primary" those directly evaluated by CPET hardware, while those derived by mathematical modeling are indicated as "secondary"

$\mathrm{ECG}$, electrocardiography; $\mathrm{HR}$, heart rate; $\mathrm{BP}$, blood pressure; $\mathrm{RER}$, respiratory exchange ratio; $\mathrm{VO}_{2}$, oxygen uptake; $\mathrm{VE}$, minute ventilation; $\mathrm{V}_{\mathrm{T}}$, tidal volume; $\mathrm{VO} \mathrm{O}_{2} \%$, percentage of peak oxygen uptake with respect to maximal theoretic $\mathrm{VO}_{2}$; $\mathrm{AT}$, anaerobic threshold; RER, respiratory exchange ratio, $\mathrm{E} / \mathrm{A}, \mathrm{E} / \mathrm{A}$ wave ratio; $\mathrm{E} / \mathrm{e}^{\prime}, \mathrm{E} / \mathrm{e}^{\prime}$ wave ratio; DT, deceleration time, TAPSE, tricuspid annular systolic excursion 
In brief, established T2DM ( $>5$ years duration) is associated with impaired cardiorespiratory fitness in the form of reduced exercise tolerance and a $20-30 \%$ reduction of $\mathrm{VO}_{2 \text { peak }}$ with respect to gender and age-matched, sedentary, obese, non-diabetic subjects. Interestingly, neither the grade of habitual physical activity $[9,10]$ nor early lactic acidosis (T2DM patients do not show different blood lactate kinetics with respect to normal subjects [15]) justify this finding. Thus, we can conclude that it is inherent to the diabetic state and increases with disease duration. Of note, a $12 \%$ reduction in $\mathrm{VO}_{2 \text { peak }}$ has been observed in first-degree relatives of T2DM subjects in comparison to accurately matched controls (also for habitual physical activity) suggesting a possible role of the genetic background [29]. On the other hand, the relationship observed between reduced $\mathrm{VO}_{2 \text { peak }}$ and poor metabolic control [11, 13, 24, 30,31] and presence of microvascular complications [12] clearly points toward a pathophysiological role for sustained hyperglycemia. The mechanism through which this can reduce $\mathrm{VO}_{2 \text { peak }}$ is not clear, since variable degrees of functional impairment in each of the systems cooperating at oxygen delivery and utilization has been observed in T2DM individuals. We will outline those abnormalities and their relationship with $\mathrm{VO}_{2 \text { peak }}$ in the following sections.

Notably, in T2DM subjects, reduced exercise capacity appears to be a predictor of all-cause mortality [32]. In 6213 men referred for clinical reasons to exercise test [33], 25\% failed to achieve a submaximal exercise capacity ( $\geq 5$ METs) and, when compared with those who achieved $>8$ METs, their age-adjusted relative mortality risk from any cause was 2.3 (95\% CI 1.5-3.5). Noteworthy, in a large cohort of T2DM subjects $(n=2867)$, multivariate analysis demonstrated an inverse, almost linear association between achieved METs and all-cause mortality [34] that was more evident in the 50-65 years age group in whom +1 METS was associated with a risk reduction of $27 \%$, while it was $16 \%$ in those $65+$ years. Cardiovascular mortality can also be predicted by poor exercise performance alike. In 609 T2DM individuals with negative ECG stress test, those with an exercise capacity $>85 \%$ of the predicted had a $48 \%$ lower chance of myocardial infarction, stroke, or death than those below or equal to $85 \%$ [35]. In a similar cohort of veterans [36], after an extensive adjustment for confounders (age, ethnicity, examination year, BMI, presence of cardiovascular disease, and cardiovascular risk factors), diabetic patients achieving $<5$ METs at exercise testing were $70 \%$ ([13254]) more likely to die for a cardiovascular event than those achieving at least 5 METs, the association being more robust and more graded for Caucasians than for African Americans [37].

\section{Determinants of reduced exercise capacity in type 2 diabetes}

During exercise, optimal oxygen delivery and utilization imply a delicate interplay of multiple physiological functions, such as pulmonary ventilation, gas exchange, cardiac output, muscle blood distribution and diffusion, skeletal muscle aerobic and force-generating capacity, as well as fatigue perception. Since each of them has been singularly reported to be impaired in T2DM without having been measured simultaneously nor selectively manipulated in intervention clinical trials, it is hard to understand which one/s of these is/are to be considered as the main determinant/s of the observed impaired aerobic capacity. Based on the review of the available evidence, we will describe in detail the differences that T2DM patients show with respect to healthy subjects at CPET (Table 2) and discuss their pathophysiologic

Table 2 Physiological meaning of the alterations observed in type 2 diabetes, and clinical usefulness of various cardiopulmonary exercise test indices in the management of diabetic patients

\begin{tabular}{|c|c|c|c|}
\hline CPET variable & Alterations seen in T2D & Pathophysiologic mechanisms & Clinical value \\
\hline Heart rate kinetics & $\begin{array}{l}\text { Chronotropic insufficiency, Attenu- } \\
\text { ated heart rate recovery }\end{array}$ & Autonomic neuropathy & Prognostic \\
\hline Exercise ECG & Eventual inducible ischemia & Epicardial vessel disease & Screening \\
\hline Exercise capacity & Reduced & Physical deconditioning? & Unknown \\
\hline Peak oxygen uptake $\left(\mathrm{VO}_{2 \max }\right)$ & Reduced & Primary myocardial impairment & Prognostic \\
\hline Oxygen kinetics & Slower & Primary myocardial impairment & Unknown \\
\hline Oxygen pulse $\left(\mathrm{VO}_{2} / \mathrm{HR}\right)$ & Reduced & Primary myocardial impairment & Prognostic \\
\hline Ventilatoy response $\left(\mathrm{VE} / \mathrm{VCO}_{2}\right)$ & Augmented & Primary ventilatory impairment & Unknown \\
\hline Peripheral oxygen extraction $\left(\mathrm{a}-\mathrm{v} \mathrm{O}_{2}\right)$ & Reduced & Skeletal muscle microcirculation impairment & Unknown \\
\hline Anaerobic threshold (AT) & $\begin{array}{l}\text { Unaltered, even in the presence of } \\
\text { autonomic dysfunction }\end{array}$ & Aerobic/anaerobic metabolism & Unknown \\
\hline $\mathrm{VO}_{2}$ at the anaerobic threshold (AT) & Possibly reduced & Unknown & Unknown \\
\hline
\end{tabular}


determinants highlighting the questions that are still open. This will be done according to four integrated pathophysiologic hypotheses, namely cardiogenic, myogenic, vasculogenic and neurogenic (Figs. 1, 2). Each hypothesis considers the impairment of a single organ as the first step in limiting exercise tolerance, with secondary involvement of the other systems through known pathophysiological interconnections.

\section{Myocardiogenic determinants}

Provided that oxygen extraction is maximal in the working muscle, the only way to deliver more oxygen to the bulk of active muscles is by increasing perfusion. During exercise, this is achieved through a rise in cardiac output that is coupled to a redistribution of blood away from less active tissues (skin and splanchnic vascular beds). The increase in cardiac output is obtained through a combination of an early increase in stroke volume (SV), plateauing approximately at $50 \%$ of peak effort, and a continuous increase of heart rate. In this paragraph we concentrate on SV and its determinants. CPET provides an indirect estimate of SV throughout a graded, progressive maximal exercise. As derived by Fick's equation (Eq. 1, where $\mathrm{CO}$ is cardiac output; $\Delta(\mathrm{a}-\mathrm{v}) \mathrm{O}_{2}$ is peripheral oxygen extraction; $\mathrm{SV}$ is stroke volume; $\mathrm{HR}$ is heart rate), oxygen pulse, calculated as $\mathrm{VO}_{2}$ divided by heart rate $\left(\mathrm{VO}_{2} / \mathrm{HR}\right)$, reflects the oxygen extraction capacity per heartbeat (Eq. 2):

$$
\begin{aligned}
& \mathrm{VO}_{2}[L / \text { min }]=\mathrm{CO} \cdot \Delta(\mathrm{a}-\mathrm{v}) \mathrm{O}_{2}=\mathrm{SV} \cdot \mathrm{HR} \cdot \Delta(\mathrm{a}-\mathrm{v}) \mathrm{O}_{2} \\
& \frac{V O_{2}}{H R}=S V \cdot \Delta(\mathrm{a}-\mathrm{v}) O_{2}
\end{aligned}
$$

If we exclude other major factors influencing oxygen delivery (namely severe impaired pulmonary or cardiac

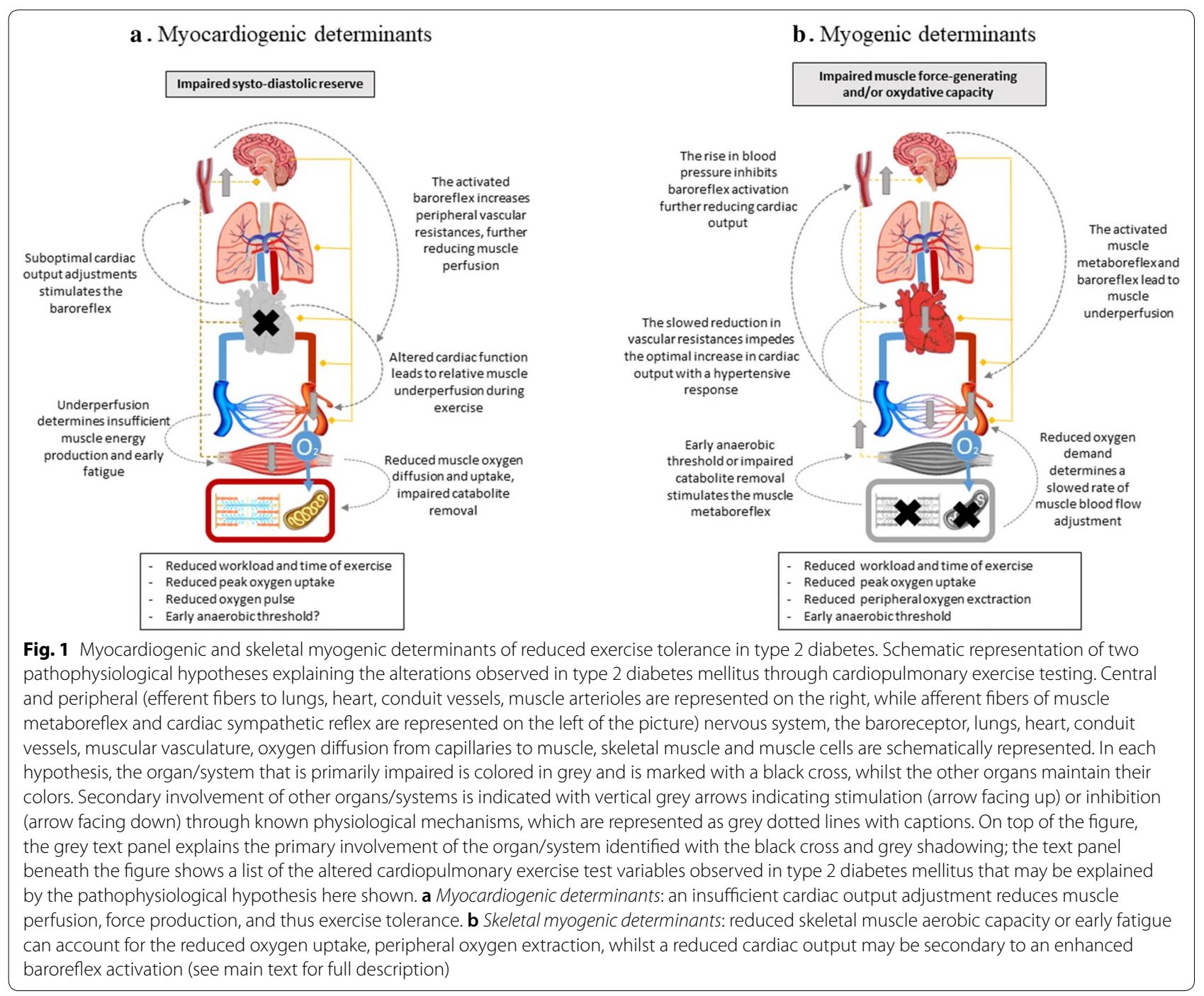




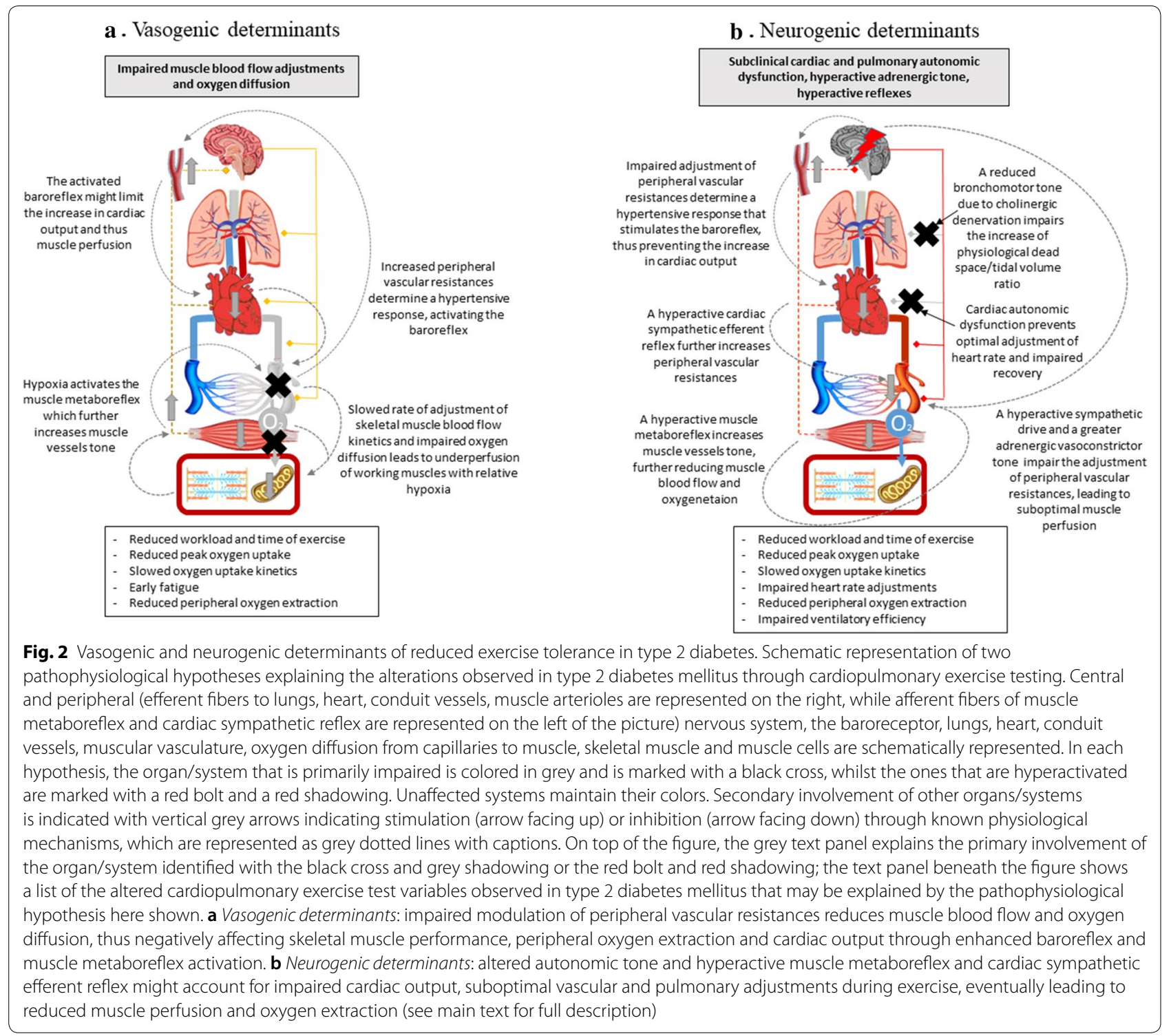

function, anemia or hypoxia), systemic $\Delta(\mathrm{a}-\mathrm{v}) \mathrm{O}_{2}$ during graded exercise has a constant and reproducible, almost linear pattern. Therefore, from Eq. 2, given the aforementioned assumptions, oxygen pulse provides an accurate [38] estimate of SV during exercise (Eq. 3):

$$
\text { if } \Delta(\mathrm{a}-\mathrm{v}) \mathrm{O}_{2} \approx \mathrm{k} \text {, then } \frac{V O_{2}}{H R} \approx \mathrm{SV}
$$

The few studies reporting this variable all concordantly show that peak oxygen pulse appears reduced by $20-30 \%$ in diabetes $[8,15,21]$ regardless of autonomic dysfunction, thus suggesting a primary cardiogenic limitation to exercise. Still, even with all the assumptions of the case, one should consider that peak oxygen pulse has a limited accuracy as a proxy for SV [39]. Thus, it is not possible to confirm a myocardial impairment based on this parameter alone. A comparison of the $\mathrm{VO}_{2} / \mathrm{HR}$ curves and their initial slope during graded exercise would offer a more reliable estimate of SV differences, but we could not find this data in T2DM without cardiac autonomic dysfunction.

In the last years, echocardiographic measures have been advantageously added to the CPET examination, providing useful information on heart morphological and functional data during incremental exercise. In asymptomatic T2DM, the use of standard echocardiography, tissue Doppler imaging, and speckle tracking technology during maximal exercise allowed the demonstration of a subtle myocardial dysfunction during exercise, which was not evident at rest [40]. In fact, despite normal baseline 
values, S' (peak systolic annular) and E' (early left ventricular filling phase) velocities of the mitral annulus measured through tissue Doppler were significantly reduced in patients with T2DM during exercise compared to controls, thus unmasking reduced systo-diastolic reserve [41-43]. Importantly, reduced $\mathrm{VO}_{2 \text { peak }}$ was associated with $S^{\prime}$ and E' and also to cardiac magnetic resonance assessed myocardial fibrosis [44]. However, other studies did not observe impaired Doppler indices, but reported LV size as a predictor of reduced oxygen uptake [45]. Finally, cardiac index reserve, a variable expressed by the combination of chronotropic index and SV index reserve, appears related to $\mathrm{VO}_{2 \max }$ as well [46], thus strengthening the possibility of causal link between subclinical diabetic cardiac myopathy and reduced exercise capacity in T2DM. Unfortunately, associations do not provide information on the causal relationships, therefore it would be more informative to evaluate the full $\mathrm{VO}_{2}$ /cardiac index curves and, more importantly, to verify whether $\mathrm{VO}_{2 \text { peak }}$ can be normalized by pharmacologically improving the cardiac inotropic function. Interestingly, the cardiac index reserve was neither related to body weight nor metabolic control but was associated with subtle functional and structural myocardial abnormalities [40]. However, this is a highly debated topic, since other studies failed in finding associations between cardiac function and exercise tolerance [47]. The lessened increase in cardiac output would explain the reduced $\mathrm{VO}_{2 \text { peak }}$ and $\mathrm{VO}_{2}$ kinetics and by preventing an adequate rise in blood pressure would enhance baroreflex stimulation, which, in turn, would impair perfusion of the exercising muscles and muscle force generation (Fig. 1a). Still, whether the insufficient increase in SV [48], in turn, depends on impaired left ventricle contractility or compliance remain to be clarified [19, 23, 49].

\section{Skeletal myogenic determinants}

A reduced aerobic capacity might be secondary to reduced muscle aerobic power. However, together with the reduced peak workload, T2DM shows early development of fatigue, that is a perceived limitation of forcegenerating capacity that requires higher intensity of effort that might eventually reduce the exercise duration. This can be highlighted by an early appearance of exhaustion during exercise and in higher fatigue with respect to controls at any given workload, even when adjusted for the reduced $\mathrm{VO}_{2 \text { peak }}[50,51]$. Still, the reasons for the decreased muscular exercise tolerance are far from being clear. One small study [25] found that insulin resistance, reduced muscle type 1 fiber content, and reduced muscle capillary density were the major contributor to the limited exercise capacity of patients with T2DM. In addition, impaired skeletal muscle mitochondrial function (measured as phosphocreatine recovery after exercise) has been reported in T2DM as well as in obese individuals [52]. Notably, in T2DM this appears more pronounced and correlates with glycated hemoglobin [53] suggesting that glucose toxicity, in addition to insulin resistance, might produce skeletal muscle dysfunction. Unfortunately, no study has simultaneously measured mitochondrial function and exercise capacity in T2DM. In any case, an impaired oxidative or force-generating muscle capacity might account for the reduced oxygen extraction and the slowed and reduced $\mathrm{VO}_{2 \text { peak }}$ (Fig. 1b).

During CPET, an indirect way to evaluate the relevance of muscle aerobic capacity is through the analysis of the aerobic threshold (AT). As exercise intensity increases, muscle fibers initiate to undergo lactic (anaerobic) metabolism, with an increase in serum lactate concentration and hydrogen ions buffered by blood bicarbonate. This produces extra carbon dioxide $\left(\mathrm{CO}_{2}\right)$ in adjunction to that derived by aerobic metabolism, thus reaching the curve breakpoint known as AT. The increase in $\mathrm{VCO}_{2}$ together with the subsequent decrease in blood $\mathrm{pH}$ stimulate a compensatory increase in the ventilatory (VE) curve, whose steep increase enables the noninvasive determination of the AT. The AT has been considered the gold standard along with $\mathrm{VO}_{2 \text { peak }}$ for the evaluation of aerobic fitness and prescription of aerobic exercise [54]. Also, while $\mathrm{VO}_{2 \text { peak }}$ is a direct measure of exercise capacity, a useful comprehensive estimate of aerobic efficiency can be obtained by measuring $\mathrm{VO}_{2}$ at AT, which also proved to predict cardiovascular and allcause mortality in the general population [55]. Few studies have measured $\mathrm{VO}_{2}$ at AT in individuals with T2DM without overt cardiovascular disease through different methods including the ventilatory equivalents, heart rate and blood lactate. The available evidence is divided, showing either normal AT, even in the presence of autonomic dysfunction $[17,18,20]$, or a reduced $\mathrm{VO}_{2}$ at AT $[11,16,31,56]$. Interestingly, a reduced $\mathrm{VO}_{2}$ at $\mathrm{AT}$ was observed in T2DM patients with microalbuminuria but not in T2DM with normoalbuminuria [57], possibly suggesting that other factors unrelated to skeletal muscle biochemistry are at play. Clearly the evaluation of this parameter as a percent of $\mathrm{VO}_{2 \text { peak }}$ would be more interesting; unfortunately, such information is still uncertain with one small study reporting a modest relative reduction [9] and other two no difference $[14,28]$ with respect to normal subjects.

Another indirect way to estimate skeletal muscle aerobic efficiency during CPET is calculating peripheral oxygen extraction $\left(\Delta(\mathrm{a}-\mathrm{v}) \mathrm{O}_{2}\right)$. During progressive maximal exercise, working muscles utilize progressively more oxygen to meet the increasing energy requests. Provided that pulmonary function is normal, the arterial oxygen 
content is usually maintained constant during exercise while the venous content is progressively reduced as a function of the extracting capacity of the working muscles. In contrast, during progressive maximal exercise, $\Delta(\mathrm{a}-\mathrm{v}) \mathrm{O}_{2}$ increases until a plateau is reached when the maximal peripheral oxygen extraction has been attained. This value can be obtained by either direct measurement of blood oxygen or can be non-invasively estimated through the Fick's equation (Eq. 4) from whole body oxygen uptake and cardiac output:

$$
\Delta(\mathrm{a}-\mathrm{v}) \mathrm{O}_{2}=\frac{\dot{V} \mathrm{O}_{2}}{\mathrm{CO}}
$$

In the diabetic population, a high prevalence of $\mathrm{HF}$ with preserved ejection fraction (HFpEF) is observed [58]; since a reduced $\Delta(\mathrm{a}-\mathrm{v}) \mathrm{O}_{2}$ using imaging-CPET has been previously demonstrated in patients with HFpEF in comparison to either controls or HF with reduced ejection fraction [59], one can hypothesize that it might play a role in T2DM alike. Indeed, only two studies have addressed this question reaching different conclusions $[19,49]$. However, it should be noted that in the study by Baldi et al. cardiac output did not differ between T2DM and control, while $\Delta(\mathrm{a}-\mathrm{v}) \mathrm{O}_{2}$ was reduced by $20 \%$ and correlated with $\mathrm{VO}_{2 \text { peak }}$. The study showing no difference was conducted in a very small group of female adolescents.

\section{Vasogenic determinants}

During skeletal muscle contraction, complex coordinated interplays exist between the cardiovascular system and the exercising muscle groups in order to optimize muscle perfusion to meet regional energy requests. Notably, peripheral vascular resistances are modulated in order to maximize the blood flow to the working muscles, since even a slightly reduced muscular oxygen partial pressure determines a reduced force production for a given motor neuron independently from a fatigue effect [60]. The mechanisms of reduced force production during mild hypoxia are numerous, encompassing either intracellular acidosis from anaerobic glucose breakdown or an increased ADP and inorganic phosphate-to-ATP ratio known to stimulate glycogenolysis producing additional intracellular acidosis [61]. These metabolic alterations lead to a reduced exercise intensity or, if the subject is willing to maintain the required exercise intensity, to a request for an increased motor neuron drive which is experienced as increased perceived exertion.

Vasodilation depends on the release of local mediators as well as on a preserved endothelial and smooth muscle cell function, which appear to be altered in T2DM. Their impact on $\mathrm{VO}_{\text {2peak }}$ emerges from correlations studies in subjects with T2DM [62] that are consistent with reduced muscle blood flow during exercise [63] and increased peripheral vascular resistance [64]. Slowed microvascular blood flow kinetics were reported in T2DM both at the beginning of exercise $[65,66]$ and during the steadystate $[67,68]$, with some heterogeneity among the studies. A slowed rate of adjustment of peripheral vascular resistance at the beginning of exercise could explain the slowed $\mathrm{VO}_{2}$ kinetics frequently observed in this population. A slower reduction in peripheral vascular resistance might also produce an increase in systemic blood pressure (as frequently observed in T2DM patients during CPET) possibly leading to a baroreflex-mediated limitation in cardiac output [69] (Fig. 2a). Several mechanisms can be recognised, namely feed-forward mechanisms (early adjustment of muscle blood flow by adenosine, potassium, nitric oxide) and feedback mechanisms (vasodilatory factors secondary to muscle metabolic demand and haemoglobin deoxygenation). In T2DM, while an impairment the feed-forward or muscle metabolic feedback mechanisms remains to be proved, reduced deoxygenation-related feedback mechanisms can be postulated. At rest, diabetic individuals show reduced ATP release from red blood cells in response to haemoglobin desaturation [70]. This mechanism appears impaired in T2DM, wherein it is activated through endothelial purinergic receptors that trigger NO-dependent and -independent arteriolar vasodilation, and is known to impact on muscle blood flow [71]. Also, several endothelial-related mechanisms of vasodilation (endothelial dysfunction) are known to be impaired in diabetes, with a substantial impact on muscle blood flow adjustments during both rest and exercise [67]. Oxidative stress has been consistently recognized as a key mediator of endothelial dysfunction in both acute [72] and chronic [73] hyperglycemia, having thus been considered amongst the main pathophysiological determinants of diabetic vascular complications. However, the relation between oxidative stress and exercise appears to be complex [74], and whether, and to what extent, this may impact on exercise tolerance in T2DM remains unclear. In a peculiar model of reversible elevated oxidative stress and endothelial dysfunction which is atrial fibrillation, cardioversion was able to improve exercise tolerance in non-diabetic subjects but resulted ineffective in subject with diabetes [21]. On the other hand, treatment with rosiglitazone was associated with an improvement of both $\mathrm{VO}_{2 \text { peak }}$ and endothelial function (measured though brachial artery flow mediated dilatation) in a small group of subjects with T2DM. Despite the small improvement in $\mathrm{VO}_{2 \text { peak }}(7 \%)$, the latter significantly correlated with the improvement in FMD [75]. Moreover, an exaggerated muscle metabolic reflex has been observed in T2DM (see paragraph 3.4) [76] a mechanisms that is known to 
produce further vasoconstriction in muscle arteries thus possibly aggravating regional blood flow impairment to the exercising muscles. In addition to muscle perfusion impairment, in T2DM an impaired oxygen diffusion from capillaries to muscle cells can be postulated. Both the increased oxygen affinity of glycated hemoglobin (displaying a left shift of the dissociation curve [77]) and the structural and functional capillaries rarefaction observed in T2DM muscles [78] might reduce oxygen diffusion from capillaries to muscle cells. To add further complexity to the scenario, it must be noted that alterations in muscle perfusion can also affect the muscle performance by inducing early fatigue independently from oxygen delivery, through an impaired catabolite removal [79].

\section{Cardiovascular neurogenic determinants}

When a neural motor impulse is sent to a skeletal muscle, a parallel impulse is given to the cardiovascular centres in the brainstem in order to increase cardiac output and central blood pressure mainly through sympathetic activation. The second determinant of increased adrenergic sympathetic tone during exercise is the muscle metaboreceptor that is stimulated by muscle mechanical and metabolic activity. These two systems are further modulated by arterial and cardiopulmonary baroreflexes that allow a beat-per-beat optimal adjustment of systemic cardiovascular parameters in order to meet regional muscle metabolic demands. During exercise the systemic peripheral vascular bed normally undergoes sympathetic adrenergic vasoconstriction known as sympathetic restrain, which is meant to reduce blood flow to non-exercising tissues. In the working muscles, this is counterbalanced by local vasodilating mechanisms (functional sympatholysis) that allow muscular blood flow to adjust to meet the regional metabolic requests rapidly. In T2DM, several defects in the neural control of the cardiovascular responses to exercise have been observed.

A reduced sympathetic innervation of the heart, as observed in diabetic cardiac autonomic neuropathy [80], can reduce the response of the heart to the sympathetic stimuli and thus lead to several resting and exercising anomalies in heart rhythm, heart rate adjustments, and exercising cardiac output adjustments [14], possibly negatively impacting on $\mathrm{VO}_{2 \text { peak }}$ and $\mathrm{O}_{2}$ kinetics. Moreover, a hyperactive sympathetic restrain can overcome the vasodilating capacities of the working muscles thus determining a reduced muscle blood flow [81], with detrimental consequences on muscle functions, increase peripheral resistances and thus limiting the increase in cardiac output though baroreflex overstimulation, and eventually also $\mathrm{VO}_{2 \text { peak }}$ (Fig. 2b). There is preliminary evidence of both a hyperactive sympathetic adrenergic drive and a greater adrenergic vasoconstrictor response to noradrenaline in T2DM subjects at rest [82] that might blunt functional sympatholysis in skeletal muscle vessels. However, its role during exercise is currently unknown. The few available studies investigating heart rate kinetics in T2DM during exercise testing provide evidence that diabetes duration and metabolic control are implicated in the chronotropic response. In fact, a slower kinetics of adjustments of heart rate $[18,83]$ is more evident in older T2DM male with longer disease duration [84] or with suboptimal glycemic control [83]. On the contrary, well-controlled men with T2DM and with relatively short disease duration $(<5$ years) do not show significant heart rate abnormalities with respect to control subjects [28]. In T2DM patients, alterations in time and frequency domains of heart rate variability at rest or in response to either exercise or other stimuli have been recognized as hallmarks of cardiac autonomic dysfunction [85], bearing a negative prognostic impact as highlighted in several major clinical trials such as ADVANCE, VADT, and ACCORD [86-88]. Noteworthy, parameters obtained during CPET examination allows the detection of earlier stages of cardiac autonomic dysfunction with respect to resting assessment [89]. In this setting, together with peak heart rate during exercise test, chronotropic incompetence and impaired heart rate recovery have a key physiological and clinical meaning, reflecting the dynamic balance between parasympathetic and sympathetic drives [90].

Chronotropic incompetence, defined as the inability to sufficiently (above $80 \%$ of maximal calculated) increase heart rate in response to increased activity, has been frequently observed in T2DM patients [91] wherein it appears related to exercise tolerance and adipose tissue mass [92]. Interestingly, it has been identified as one main factor associated with reduced exercise capacity after acute myocardial infarction in T2DM patients [93], and patients with T2DM and concomitant metabolic syndrome more frequently show chronotropic incompetence [94]. Moreover, in a mixed population of diabetic outpatients, chronotropic incompetence predicts coronary artery disease $[95,96]$ and cardiovascular events and mortality [97]. Similarly, impaired heart rate recovery, that is a slower heart rate decrease within the first 1 or $2 \mathrm{~min}$ after the cessation of physical exercise [89], is highly prevalent in the asymptomatic T2DM population [98]. It was also linked to adverse cardiovascular outcomes and increased all-cause mortality in the diabetic population beyond traditional cardiovascular risk factors $[97,99]$. On these bases, an exercise test for the detection of abnormal heart rate recovery has been proposed for routine cardiovascular screening [100]. Interestingly, slower heart rate recovery appears strongly coupled with reduced physical fitness and with chronotropic 
incompetence during exercise [98, 101]. Indeed, heart rate recovery was significantly ameliorated after a 12 weeks aerobic exercise training in 30 T2DM Chinese men [102]. Provided that aerobic training is known to improve autonomic function in cardiac neuropathy, this might support the hypothesis that altered peak and postexercise heart rate in T2DM derives mainly from subclinical autonomic dysfunction. However, further studies are necessary to confirm it.

Mechanical and metabolic stimuli produced by contracting muscle stimulate receptors and channels on the peripheral endings of thinly myelinated group III (A $\delta$-fibers) and unmyelinated group IV (C-fibers) skeletal muscle afferents that are sensitive to mechanical and metabolic (lactic acid, bradykinin, arachidonic acid, ATP) stimuli generated in the exercising muscles. The muscle afferents are integrated into the brainstem and determine the activation of sympathetic responses that increase cardiac output and peripheral vascular resistance. This reflex arch, known as muscle metaboreflex, has been demonstrated hyperactivated in T2DM [76], possibly accounting for a hypertensive blood pressure response and an impaired muscular performance secondary to reduced muscle blood flow. Interestingly, the hyperactivation of muscle metaboreflex efferents appears to be significantly correlated with diabetic disease severity [76] suggesting a pathophysiologic role for sustained hyperglycaemia and also providing a mechanistic explanation for the attenuated alterations seen in the well-controlled early T2DM.

Similarly, the cardiac sympathetic afferent reflex is a positive sympathoexcitatory neural feedback activated by a relative myocardial underperfusion (the metabolic stimuli are reactive oxygen species, acidosis, adenosine, endothelin-1, all observed to be increased in the diabetic heart [103]) that results in increases in systemic blood pressure, heart rate and myocardial contractility. This was found enhanced in T2DM animals [104], whilst in humans the exaggerated blood pressure response and the increased systemic catecholamines seen during exercise [105] might further support the hypothesis of a role for a hyperactive cardiac sympathetic afferent reflex in T2DM. However, its role in affecting cardiopulmonary performance is still to be proved.

\section{Pulmonary neurogenic determinants}

Pulmonary autonomic neuropathy might explain the alterations in ventilation and respiratory gases frequently seen in T2DM patients [15-17]. The steepness with which pulmonary ventilation (VE) rises in relation to carbon dioxide production $\left(\mathrm{VCO}_{2}\right)$ during progressive exercise, known as ventilatory equivalent for $\mathrm{CO}_{2}$ or more improperly "ventilatory efficiency", is the most used index of pulmonary function measured during CPET. The slope of the relationship between ventilation and $\mathrm{CO}_{2}$ output (VE/ $/ \mathrm{VCO}_{2}$ slope) is linear over a wide range during exercise and appears raised in several pulmonary and cardiac diseases, highlighting an inappropriate (hyper)ventilatory response to $\mathrm{VCO}_{2}$. It is worth noting that a raised $\mathrm{VE} / \mathrm{VCO}_{2}$ slope is associated with adverse prognosis [106]. Even if not confirmed by all studies [15, 21, 107], an increased $\mathrm{VE} / \mathrm{VCO}_{2}$ slope has been found in both uncomplicated T2DM and in T2DM with cardiac autonomic dysfunction, in the latter appearing even more pronounced than in uncomplicated T2DM [15-17]. Thus, T2DM subjects appear to hyperventilate in relation to $\mathrm{CO}_{2}$ production during exercise with respect to normal subjects. The pathophysiological determinants are to be searched in the modified alveolar equation:

$$
\dot{V} \mathrm{E}=863 \cdot \frac{\dot{V} \mathrm{CO}_{2}}{\mathrm{PaCO}_{2} \cdot\left[1-\frac{V_{D}}{V_{T}}\right]}
$$

where $\mathrm{PaCO}_{2}$ is the arterial partial pressure of carbon dioxide (in CPET the end-tidal $\mathrm{CO}_{2}$ partial pressure, that is $\mathrm{P}_{\mathrm{ET}} \mathrm{CO}_{2}$, is used as an estimate of $\left.\mathrm{PaCO}_{2}\right)$, and $\mathrm{V}_{\mathrm{D}} / \mathrm{V}_{\mathrm{T}}$ is the physiological dead space $\left(\mathrm{V}_{\mathrm{D}}\right) /$ tidal volume $\left(\mathrm{V}_{\mathrm{T}}\right)$ ratio [108]. From Eq. 5 we can deduce the determinants of ventilatory efficiency:

$$
\frac{\dot{V} \mathrm{E}}{\dot{V} \mathrm{CO}_{2}}=\frac{863}{\mathrm{PaCO}_{2} \cdot\left[1-\frac{V_{D}}{V_{T}}\right]}
$$

As we can see from Eq. 6, an increased VE/ $\mathrm{VCO}_{2}$ slope might derive from either a reduced $\mathrm{PaCO}_{2}$ or an increased $V_{D}$ with respect to $V_{T}$. In healthy individuals, it is known that the $\mathrm{PaCO}_{2}$ is maintained constant during exercise thanks to the appropriate increase in ventilation mainly stimulated by increased $\mathrm{CO}_{2}$ output, while the $\mathrm{V}_{\mathrm{D}}$ is progressively reduced due to progressive recruitment of non-ventilating alveoli reducing the $V_{D}$ and increasing the $V_{T}$ [108]. Available evidence suggests that both parameters are altered in T2DM. In fact, a reduced rate of decrease in $V_{D} / V_{T}$ during exercise was observed in comparison to normal subjects, displaying higher $T_{D}$ values at similar levels of ventilatory response [15]. Several mechanisms have been proposed, especially increased airways stiffness secondary to decreased bronchomotor tone due to bronchial cholinergic denervation (Fig. 2b), possibly accounting for the steeper $\mathrm{VE} / \mathrm{VCO}_{2}$ slope found in T2DM subjects with autonomic dysfunction with respect to T2DM patients free from this complication. Further, a slightly reduced $\mathrm{P}_{\mathrm{ET}} \mathrm{CO}_{2}$ at peak exercise was observed, together with an increased neuromuscular drive as measured through the pressure generated at the mouth during the first $0.1 \mathrm{~s}$ of inspiration $\left(\mathrm{P}_{0.1}\right)$ [109]. The reasons for this are less easy to explain. In fact, a reduced 
$\mathrm{P}_{\mathrm{ET}} \mathrm{CO}_{2}$ might be either the primary drive of hyperventilation or its consequence. In the first hypothesis, an altered central control of breathing must be implied, as revealed by the fact that in $\mathrm{T} 2 \mathrm{DM} \mathrm{CO} \mathrm{C}_{2}$ output can modulate the cerebral reactivity to $\mathrm{CO}_{2}$ [109]. The presence of diabetic neuropathy can further influence the cerebral reactivity to $\mathrm{CO}_{2}$ proportionately to the severity of the autonomic damage with the efferent sympathetic nervous system being involved in the increased respiratory drive seen in T2DM [107]. As a matter of fact, the increased ventilatory drive in T2DM might be secondary either to an altered $\mathrm{CO}_{2}$ set point or to a disproportionate central reactivity to $\mathrm{CO}_{2}$, or even to an impaired efferent sympathetic drive. However, it is not clear whether diabetes per se might be accountable for this alteration, or if some grade of autonomic derangement is necessary. In opposition, the reduced $\mathrm{P}_{\mathrm{ET}} \mathrm{CO}_{2}$ can also be the consequence, and not the cause, of disproportionate ventilation. This might be a result of the reduced decrease in $V_{\mathrm{D}} / \mathrm{V}_{\mathrm{T}}$. Moreover, the observed increased $\mathrm{P}_{0.1}$ might depend on mechanical constraints of the thoracic wall-pleura-lung system that are not evident at rest but become increasingly important with increased ventilatory requirements leading to relative (to $\mathrm{VCO}_{2}$ ) hyperventilation as response to increasingly energy-demanding, uncomfortable expansion of the chest wall. Intriguingly, also pulmonary ventilation (VE) appears dependent on glycemic control [30] with unknown mechanisms, possibly reinforcing the hypothesis of a structural and/or functional impairment that has been named "diabetic lung" [110]. However, it must be noted that the exercise induced VE response to $\mathrm{PaCO}_{2}$ is further modulated by a complex interplay of pulmonary vagal stretch receptors, peripheral and central chemoreceptors, baroreceptors, as well as ergoreceptors in skeletal muscles, that are difficult to isolate or completely neglect. Thus, we cannot exclude the dependence of the observed alterations in the ventilatory response from other mechanisms capable of altering the set point of $\mathrm{PaCO}_{2}$ regulation.

\section{Effect of exercise training}

As a means to general health, physical exercise has a long and storied history and -as intensely suggested by all the major guidelines [111]-remains the cornerstone of lifestyle modification as the first step of non-pharmacological therapeutic strategies for T2DM. Indeed, it is widely known that whilst a sedentary lifestyle is a major risk factor for T2DM and its complications [112], maintaining an appropriate level of physical activity proves to be protective for both incident T2DM and cardiovascular disease [113]. In this setting, in addition to improving both short-term and long-term glycaemic control in T2DM [114], exercise training shows several direct beneficial effects on various organs and systems in T2DM subjects. A 16 weeks-long progressive training programme reduced abdominal fat, fasting glycemia and insulin sensitivity beyond weight loss [115]. This might be related to either an increased skeletal muscle glucose uptake with both insulin dependent and independent mechanisms [116], or to an anti-inflammatory effect on adipose tissue. In fact, long-term (12 months), resistance+aerobic exercise training has been demonstrated to suppress cytokine production through reduced inflammatory cell infiltration of adipose tissue and improved adipocyte function [117]. Also, the autonomic tone was proved to ameliorate after 12 weeks of personalised physical training (both aerobic and resistance exercise) [102], as well as endothelial function [118], intima-media thickness, and arterial stiffness [119]. Notably, also several echocardiographic parameters can be improved with exercise training [120]. Despite these positive adaptations, however, scepticism remains surrounding the effect of exercise training on oxygen uptake and prognosis in the T2DM population. Indeed, recently, an intensive lifestyle intervention proved to be ineffective in a large cohort of T2DM patients in affecting the risk of HF development [121], wherein a higher baseline cardiorespiratory fitness, the decrease in body weight, and the improvement in oxygen uptake were all associated with a small reduction in HF risk.

Structured programs of exercise training demonstrated to improve $\mathrm{VO}_{2 \text { peak }}$ by approximately $10 \%$ in subjects with T2DM [122]. A metanalysis on 9 studies published in 2003 yields a figure of $+11 \%$, but also a standard deviation of $11 \%$, which indicates a surprisingly elevated interindividual variability. This aspect has been addressed by a large study by Pandley et al. [123], showing that up to $43 \%$ of T2DM patients undergoing structured exercise training, experience no improvement in $\mathrm{VO}_{2 \text { peak }}$. Noteworthy, only $37 \%$ of them had a clinically meaningful response $\left(\Delta \mathrm{VO}_{2 \text { peak }} \geq 5 \%\right)$. This is somewhat unexpected, since -on average- patients with T2DM are less physically active than non-diabetic subjects, and larger responses are usually observed in sedentary subjects undergoing physical exercise training than in already physically active individuals. In a group of only women, T2DM was associated with lower baseline $\mathrm{VO}_{2 \text { peak }}$ and greater improvements in response to training, but -notably- they did not achieve the same level of fitness as the non-diabetic controls did while undergoing the same programme [124]. Overall, the balance of evidence appears to suggest that exercise training is not particularly effective in increasing $\mathrm{VO}_{2 \text { peak }}$ in T2DM. Besides, these observations also indirectly suggest that muscle deconditioning does not entirely explain the lower $\mathrm{VO}_{2 \text { peak }}$ of T2DM subjects. Seemingly, obesity -which shows a high prevalence in 
T2DM population- seem not to account for this effect either, since its role appears to be blunted across all BMI groups when cardiorespiratory fitness is considered [125]. Although a randomized controlled trial directly addressing this question is lacking, few indirect evidences provide further support to this hypothesis. An accurate study in middle aged non-diabetic subjects, estimated an impact of exercise training on $\mathrm{VO}_{2 \text { peak }}$ that is slightly larger in quantitative terms (15\%) and also more predictable (Standard Deviation: $8 \%$ ) than what is generally reported in T2DM subjects [126], but still confirming the reduced response of T2DM patients to exercise training. Interestingly, the same observations seem to hold true also in diabetic subject with HF, wherein a training programme produced a smaller mean increase in $\mathrm{VO}_{2 \text { peak }}$ than in non-diabetic counterparts $(0.5 \pm 2.4$ vs $0.9 \pm 2.6 \mathrm{~mL} \mathrm{~kg}-1 \mathrm{~min}-1 ; \mathrm{P}=0.03)$ [127].

In this scenario, three main sources of variability can be identified: namely, the type, the intensity, and the duration of the training performed. Indeed, in a large cohort of T2DM subjects, only the combination of resistance and aerobic training was able to increase $\mathrm{VO}_{2 \text { peak }}$ by $5 \%$, whilst neither of the same interventions alone resulted effective [128]. Secondarily, in a recent study the high intensity programme was able to produce a $20 \%$ increase of $\mathrm{VO}_{2 \text { peak }}$, whereas moderate intensity resulted ineffective [129]. Additionally, high intensity interval training was proved more effective than moderate-intensity continuous training in improving cardiopulmonary performance in prediabetes and T2DM [130], suggesting that higher intensities are required to achieve significative results. However, since moderate intensity continuous training + resistance training increased oxygen uptake in T2DM patients after one year of supervised training -while high intensity interval training did not after the same follow-up[131], the duration of the training performed should also be considered as a key factor.

The molecular background for the impaired response to exercise training in T2DM could depend on the toxic effect of diabetes on mitochondrial functions. Indeed, the effect of training on cellular respiration appears to be blunted in subjects with T2DM: even in patients with early-onset T2DM, abnormalities in the exercisedependent pathway that regulates the expression of PGC-1alpha and Mfn2 have been demonstrated [132]. Proteomic studies seem to confirm this hypothesis, showing no change in protein expression in T2DM skeletal muscle in response to exercise, specifically at the site of the mitochondrial electron transport chain [133]. In addition, diabetes-related endothelial dysfunction might also explain the reduced increase in cardiorespiratory fitness after exercise training. Whilst the improvement in endothelial function is associated with the increased cardiorespiratory fitness in both T2DM subjects and the general population [134], the increase appears smaller in the first ones $[118,134]$. Another explanation for the reduced sensitivity of $\mathrm{VO}_{2 \text { peak }}$ to physical exercise in T2DM could be related to an interference of glucose lowering drugs with mitochondria. As recently shown, the ongoing treatment with metformin almost completely prevented the increase in $\mathrm{VO}_{2 \text { peak }}$ induced by exercise training in T2D patients, as well as the exercise-mediated increase in skeletal muscle mitochondrial respiration [135]. However, since improvements in $\mathrm{VO}_{2 \text { peak }}$ are comparable between $\mathrm{T} 2 \mathrm{D}$ offspring and control subjects $(+15 \%)$, it is unlikely to postulate that a different skeletal muscle mitochondria response to exercise is present before the onset of diabetes [136]. The quantitative effect of exercise training on exercise tolerance in T2DM, as well as the prognostic value in terms of HF incidence and the pathophysiological mechanisms implicated, remain elusive. Further studies are intensely needed.

\section{Future directions}

Whilst the evidence of reduced exercise capacity and tolerance in T2DM patients is quite homogeneous, the same cannot be said for its physiological determinants. Given that exercise intolerance is the hallmark of HF, and that the pathophysiological link between T2DM and HFpEF is still an intensely discussed topic, a better understanding of the determinants of the early alterations that prelude to overt HF in uncomplicated T2DM could be of great value. First, a more detailed description of the cardiopulmonary performance of T2DM subjects with exercise intolerance, in comparison to those with normal exercise tolerance, would establish which is/are the major determinant/s and allow the design of focused intervention studies. Second, well-designed intervention trials using imaging-CPET could help confirm or weaken the importance of each of the four hypotheses that here we propose. Based on the present work, we identified few intervention trials that could help dissect the relevance of each physiological system in exercise intolerance in T2DM. The simultaneous comparison of peak cardiac output and peak $\Delta(\mathrm{a}-\mathrm{v}) \mathrm{O}_{2}$ according to the achieved $\mathrm{VO}_{2 \text { peak }}$ in a large cohort would be required to establish whether the most important defect is in the heart or in the skeletal muscle. Conversely, being the role of vasodilatation in limiting exercise tolerance in diabetes extremely difficult to be established, only a well-designed interventional study with exercise skeletal muscle perfusion enhancers (like dipyridamole or theophylline) in subjects with low exercise tolerance could test the hypothesis. A trial with a low dose of a sympatholytic 
agent like clonidine or phentolamine could provide this information since it did not limit the time to exhaustion in normal subjects, while having minor systemic effects [137]. Furthermore, the role of a possible pulmonary neurogenic limitation to the decrease in $\mathrm{V}_{\mathrm{D}} / \mathrm{V}_{\mathrm{T}}$ might be highlighted by the change of $\mathrm{VE} / \mathrm{VCO}_{2}$ slope in response to bronchodilators acting on cholinergic receptors (responsible for the bronchomotor tone and its adjustments during graded exercise). The questions that remain open and the experiments required to address them are schematized in Fig. 3. Imaging-CPET might also be used to dissect the mechanisms of improvement of $\mathrm{VO}_{2 \text { peak }}$ after different types, intensities, and duration of exercise training. In this setting, it might play a pivotal role

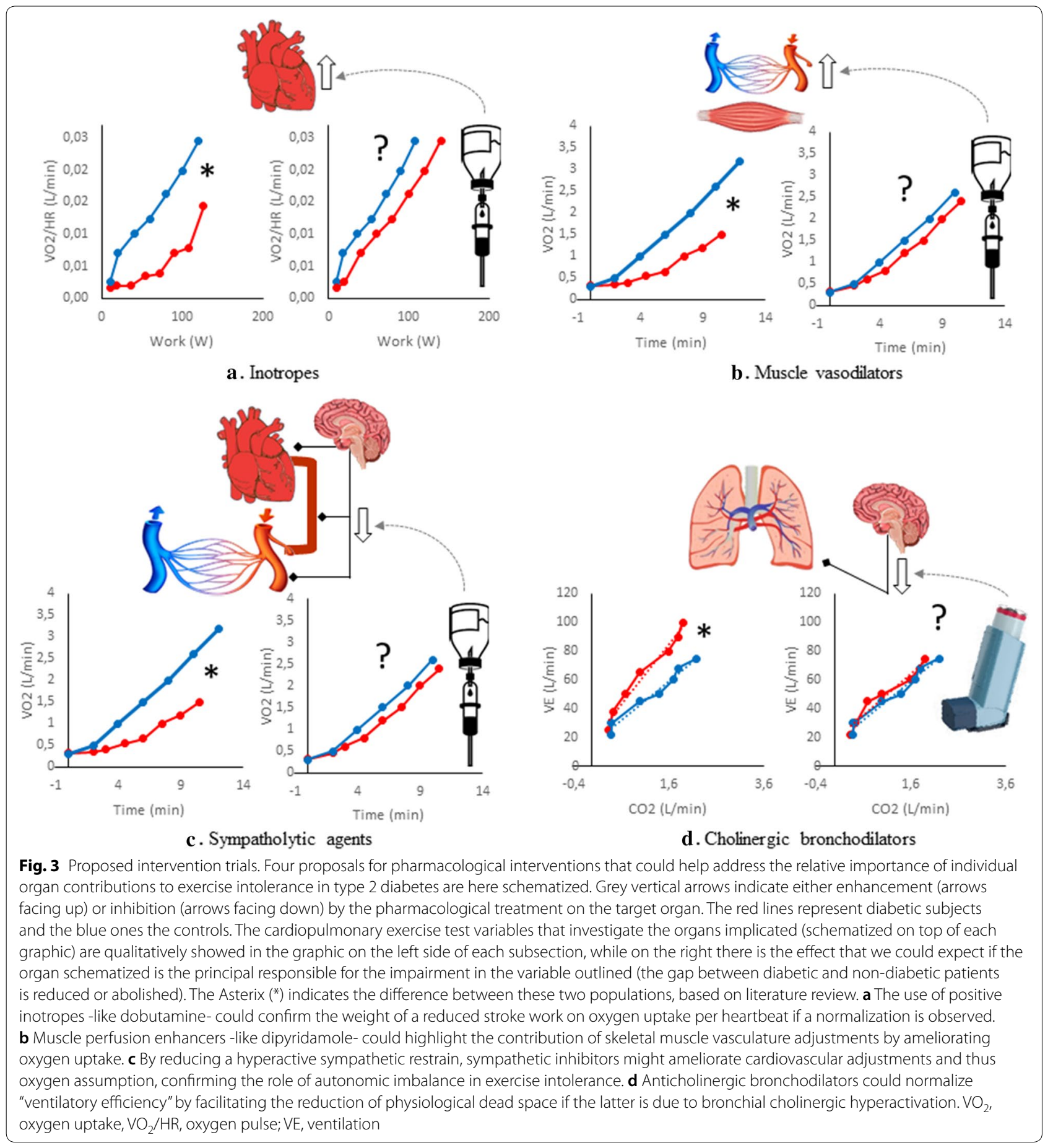


in shedding light on the physiological mechanisms (heart vs lung vs skeletal muscle vs blood vessels vs nervous system) that underpin the beneficial effects of physical exercise in T2DM. Furthermore, imaging-CPET might also be considered for rehabilitation programmes in T2DM patients. Currently, T2DM per se is not an official indication for performing CPET, a population in which the 6 min walking test is often seen as the first choice-since it is validated against exercise test [138]-yet quite uninformative. On the contrary, CPET allows a precise estimate of oxygen dynamics (which is also preserved in patients with coronary artery disease, appearing safe and very informative-even at very reduced workloads [139]), together with a multivariable cardiopulmonary, muscular and metabolic assessment; therefore, it might be envisaged not only for the assessment of cardiorespiratory fitness, but also for HF risk stratification and rehabilitation prescription and surveillance alike.

\section{Concluding remarks}

There is solid evidence indicating reduced exercise tolerance in T2DM patients free from overt cardiovascular and pulmonary disease in the form of reduced peak workload, peak oxygen assumption, oxygen pulse, as well as reduced "ventilatory efficiency". Based on the multiparametric evaluation provided by imaging-CPET, four pathophysiological determinants can explain the observed cardiopulmonary alterations, namely (1) myocardiogenic (inadequate cardiac output adjustments); (2) skeletal myogenic (reduced force-generating capacity and early fatigue); (3) vasogenic (suboptimal perfusion and oxygenation of working muscles); and (4) neurogenic (impaired neural control of cardiovascular and pulmonary adjustments during exercise). While each hypothesis alone can potentially explain the majority of the CPET alterations observed, seemingly different combinations exist-depending largely on diabetes duration and degree of metabolic control-in any given subject. Well-designed intervention studies using the multivariable approach offered by imagingCPET might allow a better dissection of the role that each of the four hypotheses here proposed can have in determining an impaired exercise capacity. ImagingCPET might also be a key technique for the dissection of the effects of physical exercise in T2DM. ImagingCPET can be envisaged as a key tool for cardiovascular risk stratification, prognostication and rehabilitation in T2DM, capable of bringing pathophysiological insights into exercise intolerance and -possibly- the progression to overt HF.

\section{Limitations}

The aim of our work was not to produce a systematic review, but a comment on the pathophysiology of exercise intolerance in T2DM; thus, we did not use the PRISMA guidelines. The methodology used for literature review was a search on Pubmed central with the keywords "type 2 diabetes" and a union of many keywords for exercise intolerance (e.g.: exercise tolerance, aerobic fitness, aerobic capacity, cardiopulmonary function, oxygen uptake, oxygen consumption, cardiopulmonary characterization, exercise capacity, exercise tolerance, exercise intolerance, diabetic cardiomyopathy, pulmonary function, lung function, exercise echocardiography, exercise imaging) and then looking for similar results among the suggested papers and through the references, aiming at a narrative review instead of a systematic review/metanalysis. We acknowledge that a physiology/narrative review does not have the same accuracy as a systematic review, thus we recognize it as a major limitation.

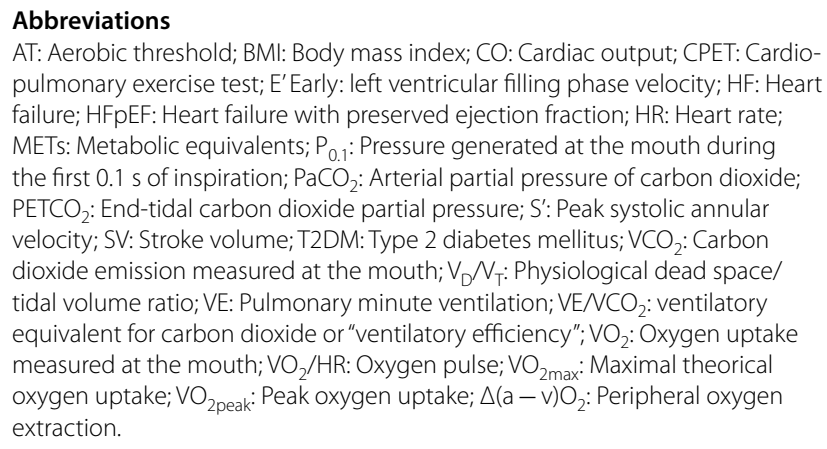
pulmonary exercise test; E' Early: left ventricular filling phase velocity; HF: Heart failure; HFpEF: Heart failure with preserved ejection fraction; HR: Heart rate; METs: Metabolic equivalents; $P_{0.1}$ : Pressure generated at the mouth during the first $0.1 \mathrm{~s}$ of inspiration; $\mathrm{PaCO}_{2}$ : Arterial partial pressure of carbon dioxide; $\mathrm{PETCO}_{2}$ : End-tidal carbon dioxide partial pressure; $\mathrm{S}^{\prime}$ : Peak systolic annular velocity; SV: Stroke volume; T2DM: Type 2 diabetes mellitus; $\mathrm{VCO}_{2}$ : Carbon dioxide emission measured at the mouth; $\mathrm{V}_{\mathrm{D}} \mathrm{V}_{\mathrm{T}}$ : Physiological dead space/ tidal volume ratio; VE: Pulmonary minute ventilation; VE $/ \mathrm{VCO}_{2}$ : ventilatory equivalent for carbon dioxide or "ventilatory efficiency"; $\mathrm{VO}_{2}$ : Oxygen uptake measured at the mouth; $\mathrm{VO}_{2} / \mathrm{HR}$ : Oxygen pulse; $\mathrm{VO}_{2 \text { max }}$ : Maximal theorical oxygen uptake; $\mathrm{VO}_{2 \text { peak }}$ : Peak oxygen uptake; $\triangle(\mathrm{a}-\mathrm{v}) \mathrm{O}_{2}$ : Peripheral oxygen extraction.

\section{Acknowledgements}

Not applicable.

\section{Authors' contributions}

LN performed the review of the literature, wrote the manuscript and ideated and produced the figures. PS performed the review of the literature and produced the tables. NRP provided a substantial contribution to the interpretation of the data and critically revised the manuscript. AN conceived and designed the paper, provided a substantial contribution to the analysis and interpretation of the data, and critically revised the manuscript. All authors read and approved the final manuscript.

\section{Funding}

No funding was required for writing this paper.

Availability of data and materials

Not applicable.

Ethics approval and consent to participate

Not applicable.

\section{Consent for publication}

All the Authors gave their consent to publication.

\section{Competing interests}

The authors have no conflict of interest to declare. 


\section{Author details}

${ }^{1}$ Metabolism, Nutrition and Atherosclerosis Lab, Dietologia Universitaria, Pisa, Italy. ${ }^{2}$ Cardiopulmonary Test Lab, Department of Clinical and Experimental Medicine, University of Pisa, Via Savi 10, 56126 Pisa, Italy.

Received: 29 April 2020 Accepted: 29 August 2020 Published online: 05 September 2020

\section{References}

1. Lehrke M, Marx N. Diabetes mellitus and heart failure. Am J Cardiol. 2017;120(1S):S37-47.

2. Mancini DM, Eisen H, Kussmaul W, Mull R, Edmunds LH Jr, Wilson JR. Value of peak exercise oxygen consumption for optimal timing of cardiac transplantation in ambulatory patients with heart failure. Circulation. 1991;83(3):778-86.

3. Blair SN, Kohl HW, Paffenbarger RS, Clark DG, Cooper KH, Gibbons LW. Physical fitness and all-cause mortality. A prospective study of healthy men and women. JAMA. 1989:262(17):2395-401.

4. Nauman J, Nes BM, Lavie CJ, Jackson AS, Sui X, Coombes JS, Blair SN Wisloff $U$. Prediction of cardiovascular mortality by estimated cardiorespiratory fitness independent of traditional risk factors: the HUNT study. Mayo Clin Proc. 2017:92(2):218-27.

5. Look ARG, Wing RR, Bolin P, Brancati FL, Bray GA, Clark JM, Coday $M$, Crow RS, Curtis JM, Egan CM, et al. Cardiovascular effects of intensive lifestyle intervention in type 2 diabetes. $\mathrm{N}$ Engl J Med. 2013;369(2):145-54

6. Guazzi M, Bandera F, Ozemek C, Systrom D, Arena R. Cardiopulmonary exercise testing: what is its value? J Am Coll Cardiol. 2017:70(13):1618-36.

7. Kitahara Y, Hattori N, Yokoyama A, Yamane K, Sekikawa K, Inamizu $\mathrm{T}$, Kohno $\mathrm{N}$. The influence of lung function on exercise capacity in patients with type 2 diabetes. Hiroshima J Med Sci. 2010;59(1):7-13.

8. Bottini P, Tantucci C, Scionti L, Dottorini ML, Puxeddu E, Reboldi G, Bolli GB, Casucci G, Santeusanio F, Sorbini CA, et al. Cardiovascular response to exercise in diabetic patients: influence of autonomic neuropathy of different severity. Diabetologia. 1995;38(2):244-50.

9. Kjaer M, Hollenbeck CB, Frey-Hewitt B, Galbo H, Haskell W, Reaven GM. Glucoregulation and hormonal responses to maximal exercise in noninsulin-dependent diabetes. J Appl Physiol (1985). 1990;68(5):2067-74

10. Schneider SH, Amorosa LF, Khachadurian AK, Ruderman NB. Studies on the mechanism of improved glucose control during regular exercise in type 2 (non-insulin-dependent) diabetes. Diabetologia. 1984;26(5):355-60.

11. Vanninen E, Uusitupa M, Remes J, Siitonen O, Laitinen J, Länsimies E, Pyörälä K. Relationship between hyperglycaemia and aerobic power in men with newly diagnosed type 2 (non insulin-dependent) diabetes. Clin Physiol. 1992;12(6):667-77.

12. Estacio RORJ, Wolfel EE, Jeffers B, Dickenson M, Schrier RW. The association between diabetic complications and exercise capacity in NIDDM patients. Diabetes Care. 1998;21(2):291-5.

13. Demir I, Ermis C, Altunbas H, Balci MK. Serum HbA1cLevels and exercise capacity in diabetic patients. Jpn Heart J. 2001;42(5):607-16.

14. Roy TM, Peterson HR, Snider HL, Cyrus J, Broadstone VL, Fell RD, Rothchild AH, Samols E, Pfeifer MA. Autonomic influence on cardiovascular performance in diabetic subjects. Am J Med. 1989;87(4):382-8.

15. Tantucci C, Bottini P, Dottorini ML, Puxeddu E, Casucci G, Scionti L, Sorbini CA. Ventilatory response to exercise in diabetic subjects with autonomic neuropathy. J Appl Physiol (1985). 1996;81(5):1978-86.

16. Francisco CO, Catai AM, Moura-Tonello SCG, Lopes SLB, Benze BG, Del Vale AM, Leal AMO. Cardiorespiratory fitness, pulmonary function and C-reactive protein levels in nonsmoking individuals with diabetes. Braz J Med Biol Res. 2014;47(5):426-31.

17. Benbassat CA, Stern E, Blum I, Kramer M, Lebzelter J, Fink G. Pulmonary function in patients with diabetes mellitus. Am J Med Sci. 2001;322(3):127-32.

18. Regensteiner JG, Bauer TA, Reusch JE, Brandenburg SL, Sippel JM, Vogelsong AM, Smith S, Wolfel EE, Eckel RH, Hiatt WR. Abnormal oxygen uptake kinetic responses in women with type II diabetes mellitus. J Appl Physiol. 1998;85(1):310-7.
19. Baldi JC, Aoina JL, Oxenham HC, Bagg W, Doughty RN. Reduced exercise arteriovenous $\mathrm{O} 2$ difference in Type 2 diabetes. J Appl Physiol. 2003:94(3):1033-8.

20. Kremser CB, Levitt NS, Borow KM, Jaspan JB, Lindbloom C, Polonsky KS, Leff AR. Oxygen uptake kinetics during exercise in diabetic neuropathy. J Appl Physiol. 1988;65(6):2665-71.

21. Guazzi M, Belletti S, Bianco E, Lenatti L, Guazzi MD. Endothelial dysfunction and exercise performance in lone atrial fibrillation or associated with hypertension or diabetes: different results with cardioversion. Am J Physiol Heart Circ Physiol. 2006;291(2):H921-8.

22. Kiely C, Rocha J, O'Connor E, O'Shea D, Green S, Egana M. Influence of menopause and Type 2 diabetes on pulmonary oxygen uptake kinetics and peak exercise performance during cycling. Am J Physiol Regul Integr Comp Physiol. 2015;309(8):R875-83.

23. Mac Ananey O, Malone J, Warmington S, O'Shea D, Green S, Egana M. Cardiac output is not related to the slowed $\mathrm{O} 2$ uptake kinetics in type 2 diabetes. Med Sci Sports Exerc. 2011;43(6):935-42.

24. Gurdal A, Kasikcioglu E, Yakal S, Bugra Z. Impact of diabetes and diastolic dysfunction on exercise capacity in normotensive patients without coronary artery disease. Diab Vasc Dis Res. 2015;12(3):181-8.

25. Segerstrom AB, Elgzyri T, Eriksson KF, Groop L, Thorsson O, Wollmer P. Exercise capacity in relation to body fat distribution and muscle fibre distribution in elderly male subjects with impaired glucose tolerance, type 2 diabetes and matched controls. Diabetes Res Clin Pract. 2011;94(1):57-63.

26. Bjornstad P, Truong U, Dorosz JL, Cree-Green M, Baumgartner A, Coe G, Pyle L, Regensteiner JG, Reusch JE, Nadeau KJ. Cardiopulmonary Dysfunction and Adiponectin in Adolescents With Type 2 Diabetes. J Am Heart Assoc. 2016;5(3):e002804.

27. Nadeau KJ, Zeitler PS, Bauer TA, Brown MS, Dorosz JL, Draznin B, Reusch JE, Regensteiner JG. Insulin resistance in adolescents with type 2 diabetes is associated with impaired exercise capacity. J Clin Endocrinol Metab. 2009;94(10):3687-95.

28. Caron J, duManoir GR, Labrecque L, Chouinard A, Ferland A, Poirier P, Legault S, Brassard P. Impact of type 2 diabetes on cardiorespiratory function and exercise performance. Physiol Rep. 2017;5(4):e13145.

29. Thamer C, Stumvoll M, Niess A, Tschritter O, Haap M, Becker R, Shirkavand F, Bachmann O, Rett K, Volk A, et al. Reduced skeletal muscle oxygen uptake and reduced beta-cell function: two early abnormalities in normal glucose-tolerant offspring of patients with type 2 diabetes. Diabetes Care. 2003;26(7):2126-32.

30. Brassard P, Ferland A, Bogaty P, Desmeules M, Jobin J, Poirier P. Influence of glycemic control on pulmonary function and heart rate in response to exercise in subjects with type 2 diabetes mellitus. Metabolism. 2006;55(11):1532-7.

31. Moxley EW, Smith D, Quinn L, Park C. Relationships between glycemic control and cardiovascular fitness. Biol Res Nurs. 2018:20(4):422-8.

32. Church TS, LaMonte MJ, Barlow CE, Blair SN. Cardiorespiratory fitness and body mass index as predictors of cardiovascular disease mortality among men with diabetes. Arch Intern Med. 2005;165(18):2114-20.

33. Myers J, Prakash M, Froelicher V, Do D, Partington S, Atwood JE. Exercise capacity and mortality among men referred for exercise testing. N Engl J Med. 2002;346(11):793-801.

34. Nylen ES, Kokkinos P, Myers J, Faselis C. Prognostic effect of exercise capacity on mortality in older adults with diabetes mellitus. J Am Geriatr Soc. 2010;58(10):1850-4

35. Pierre-Louis B, Aronow WS, Yoon JH, Ahn C, DeLuca AJ, Weiss MB Kalapatapu K, Pucillo AL, Monsen CE. Incidence of myocardial infarction or stroke or death at 47-month follow-up in patients with diabetes and a predicted exercise capacity $<$ or $=85 \%$ vs $>85 \%$ during an exercise treadmill sestamibi stress test. Prev Cardiol. 2010;13(1):14-7.

36. McAuley PA, Myers JN, Abella JP, Tan SY, Froelicher VF. Exercise capacity and body mass as predictors of mortality among male veterans with type 2 diabetes. Diabetes Care. 2007;30(6):1539-43.

37. Kokkinos P, Myers J, Nylen E, Panagiotakos DB, Manolis A, Pittaras A, Blackman MR, Jacob-Issac R, Faselis C, Abella J, et al. Exercise capacity and all-cause mortality in African American and Caucasian men with type 2 diabetes. Diabetes Care. 2009;32(4):623-8.

38. Bhambhani Y, Norris S, Bell G. Prediction of stroke volume from oxygen pulse measurements in untrained and trained men. Can J Appl Physiol. 1994;19(1):49-59. 
39. American Thoracic S. American College of chest P: aTS/ACCP statement on cardiopulmonary exercise testing. Am J Respir Crit Care Med. 2003;167(2):211-77.

40. Jellis CL, Stanton T, Leano R, Martin J, Marwick TH. Usefulness of at rest and exercise hemodynamics to detect subclinical myocardial disease in type 2 diabetes mellitus. Am J Cardiol. 2011;107(4):615-21.

41. Ha JW, Lee HC, Kang ES, Ahn CM, Kim JM, Ahn JA, Lee SW, Choi EY, Rim SJ, Oh JK, et al. Abnormal left ventricular longitudinal functional reserve in patients with diabetes mellitus: implication for detecting subclinical myocardial dysfunction using exercise tissue Doppler echocardiography. Heart. 2007;93(12):1571-6.

42. Jellis $C L$, Jenkins $C$, Leano $R$, Martin JH, Marwick TH. Reduced endsystolic pressure-volume ratio response to exercise: a marker of subclinical myocardial disease in type 2 diabetes. Circ Cardiovasc Imaging 2010;3(4):443-9.

43. Zahiti BF, Gorani DR, Gashi FB, Gjoka SB, Zahiti LB, Haxhiu BS, Kamberi LS. Left ventricular diastolic dysfunction in asymptomatic type 2 diabetic patients: detection and evaluation by tissue Doppler imaging. Acta Inform Med. 2013;21(2):120-3.

44. Jellis C, Wright J, Kennedy D, Sacre J, Jenkins C, Haluska B, Martin J, Fenwick J, Marwick TH. Association of imaging markers of myocardial fibrosis with metabolic and functional disturbances in early diabetic cardiomyopathy. Circ Cardiovasc Imaging. 2011;4(6):693-702.

45. Roberts TJ, Burns AT, Maclsaac RJ, Maclsaac Al, Prior DL, La Gerche A. Exercise capacity in diabetes mellitus is predicted by activity status and cardiac size rather than cardiac function: a case control study. Cardiovasc Diabetol. 2018;17(1):44.

46. Sacre JW, Jellis CL, Haluska BA, Jenkins C, Coombes JS, Marwick TH, Keske MA. Association of Exercise Intolerance in Type 2 Diabetes With Skeletal Muscle Blood Flow Reserve. JACC Cardiovasc Imaging. 2015:8(8):913-21.

47. Roberts TJ, Barros-Murphy JF, Burns AT, Maclsaac RJ, Maclsaac Al, Prior DL, La Gerche A. Reduced Exercise capacity in diabetes mellitus is not associated with impaired deformation or twist. J Am Soc Echocardiogr. 2020;33(4):481-9.

48. Mustonen JN, Uusitupa MIJ, Tahvanainen K, Talwar S, Laakso M, Länsimies E, Kuikka JT, Pyörälä K. Impaired left ventricular systolic function during exercise in middle-aged insulin-dependent and noninsulindependent diabetic subjects without clinically evident cardiovascular disease. Am J Cardiol. 1988:62(17):1273-9.

49. Gusso S, Hofman P, Lalande S, Cutfield W, Robinson E, Baldi JC. Impaired stroke volume and aerobic capacity in female adolescents with type 1 and type 2 diabetes mellitus. Diabetologia. 2008;51(7):1317-20.

50. Huebschmann AG, Reis EN, Emsermann C, Dickinson LM, Reusch JE, Bauer TA, Regensteiner JG. Women with type 2 diabetes perceive harder effort during exercise than nondiabetic women. Appl Physiol Nutr Metab. 2009;34(5):851-7.

51. Kim YS, Seifert T, Brassard P, Rasmussen P, Vaag A, Nielsen HB, Secher NH, van Lieshout JJ. Impaired cerebral blood flow and oxygenation during exercise in type 2 diabetic patients. Physiol Rep. 2015;3(6):e12430.

52. Koliaki C, Roden M. Alterations of mitochondrial function and insulin sensitivity in human obesity and diabetes mellitus. Annu Rev Nutr. 2016:36:337-67.

53. Schrauwen-Hinderling VB, Kooi ME, Hesselink MK, Jeneson JA, Backes WH, van Echteld CJ, van Engelshoven JM, Mensink M, Schrauwen P. Impaired in vivo mitochondrial function but similar intramyocellular lipid content in patients with type 2 diabetes mellitus and BMImatched control subjects. Diabetologia. 2007;50(1):113-20.

54. Colberg SR, Sigal RJ, Fernhall B, Regensteiner JG, Blissmer BJ, Rubin RR, Chasan-Taber L, Albright AL, Braun B, American College of Sports $M$, et al. Exercise and type 2 diabetes: the American College of Sports Medicine and the American diabetes association: joint position statement executive summary. Diabetes Care. 2010;33(12):2692-6.

55. Kunutsor SK, Kurl S, Khan H, Zaccardi F, Rauramaa R, Laukkanen JA. Oxygen uptake at aerobic threshold is inversely associated with fatal cardiovascular and all-cause mortality events. Ann Med. 2017:49(8):698-709.

56. Emerenziani GP, Gallotta MC, Migliaccio S, Greco EA, Marocco C, di Lazzaro L, Fornari R, Lenzi A, Baldari C, Guidetti L. Differences in ventilatory threshold for exercise prescription in outpatient diabetic and sarcopenic obese subjects. Int J Endocrinol. 2016;2016:6739150.
57. Lau AC, Lo MK, Leung GT, Choi FP, Yam LY, Wasserman K. Altered exercise gas exchange as related to microalbuminuria in type 2 diabetic patients. Chest. 2004;125(4):1292-8.

58. Lindman BR, Davila-Roman VG, Mann DL, McNulty S, Semigran MJ, Lewis GD, de las Fuentes L, Joseph SM, Vader J, Hernandez AF, et al. Cardiovascular phenotype in HFpEF patients with or without diabetes: a RELAX trial ancillary study. J Am Coll Cardiol. 2014;64(6):541-9.

59. Pugliese NR, Mazzola M, Fabiani I, Gargani L, De Biase N, Pedrinelli R, Natali A, Dini FL. Haemodynamic and metabolic phenotyping of hypertensive patients with and without heart failure by combining cardiopulmonary and echocardiographic stress test. Eur J Heart Fail. 2020;22(3):458-68.

60. Wright JR, McCloskey DI, Fitzpatrick RC. Effects of systemic arterial blood pressure on the contractile force of a human hand muscle. J Appl Physiol. 2000;88(4):1390-6.

61. Westerblad H, Allen DG. Cellular mechanisms of skeletal muscle fatigue. Adv Exp Med Biol. 2003;538:563-70 discussion 571

62. Montero D. The association of cardiorespiratory fitness with endothelial or smooth muscle vasodilator function. Eur J Prev Cardiol. 2015;22(9):1200-11.

63. Lalande S, Gusso S, Hofman PL, Baldi JC. Reduced leg blood flow during submaximal exercise in type 2 diabetes. Med Sci Sports Exerc. 2008;40(4):612-7.

64. O'Connor E, Green S, Kiely C, O'Shea D, Egana M. Differential effects of age and type 2 diabetes on dynamic vs. peak response of pulmonary oxygen uptake during exercise. J Appl Physiol. 2015;118(8):1031-9.

65. Bauer TA, Reusch JE, Levi M, Regensteiner JG. Skeletal muscle deoxygenation after the onset of moderate exercise suggests slowed microvascular blood flow kinetics in type 2 diabetes. Diabetes Care. 2007;30(11):2880-5.

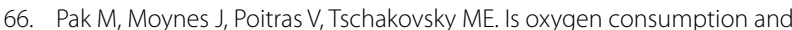
oxygen delivery during leg exercise compromised in type II diabetes? Med Sci Sports Exercise. 2010;42:242.

67. Kingwell BA, Formosa M, Muhlmann M, Bradley SJ, McConell GK. Type 2 diabetic individuals have impaired leg blood flow responses to exercise: role of endothelium-dependent vasodilation. Diabetes Care. 2003;26(3):899-904.

68. Groen MB, Knudsen TA, Finsen SH, Pedersen BK, Hellsten $Y$, Mortensen SP. Reduced skeletal-muscle perfusion and impaired ATP release during hypoxia and exercise in individuals with type 2 diabetes. Diabetologia. 2019;62(3):485-93.

69. de Moura-Tonello SC, Porta A, Marchi A, de Almeida Fagundes A, Francisco Cde O, Rehder-Santos P, Milan-Mattos JC, Simoes RP, Gois Mde O, Catai AM. Cardiovascular variability analysis and baroreflex estimation in patients with type 2 diabetes in absence of any manifest neuropathy. PLOS ONE. 2016:11(3):e0148903.

70. Sprague RS, Stephenson AH, Bowles EA, Stumpf MS, Lonigro AJ. Reduced expression of $\mathrm{G}(\mathrm{i})$ in erythrocytes of humans with type 2 diabetes is associated with impairment of both CAMP generation and ATP release. Diabetes. 2006;55(12):3588-93.

71. Thaning P, Bune LT, Hellsten Y, Pilegaard H, Saltin B, Rosenmeier JB. Attenuated purinergic receptor function in patients with type 2 diabetes. Diabetes. 2010;59(1):182-9.

72. Mah E, Noh SK, Ballard KD, Matos ME, Volek JS, Bruno RS. Postprandial hyperglycemia impairs vascular endothelial function in healthy men by inducing lipid peroxidation and increasing asymmetric dimethylarginine:arginine. J Nutr. 2011;141(11):1961-8.

73. Su Y, Liu XM, Sun YM, Jin HB, Fu R, Wang YY, Wu Y, Luan Y. The relationship between endothelial dysfunction and oxidative stress in diabetes and prediabetes. Int J Clin Pract. 2008;62(6):877-82.

74. Finkler $M$, Lichtenberg $D$, Pinchuk I. The relationship between oxidative stress and exercise. J Basic Clin Physiol Pharmacol. 2014;25(1):1-11.

75. Regensteiner JG, Bauer TA, Reusch JE. Rosiglitazone improves exercise capacity in individuals with type 2 diabetes. Diabetes Care. 2005;28(12):2877-83.

76. Holwerda SW, Restaino RM, Manrique C, Lastra G, Fisher JP, Fadel PJ. Augmented pressor and sympathetic responses to skeletal muscle metaboreflex activation in type 2 diabetes patients. Am J Physiol Heart Circ Physiol. 2016;310(2):H300-9.

77. De Rosa MC, Sanna MT, Messana I, Castagnola M, Galtieri A, Tellone E, Scatena R, Botta B, Botta M, Giardina B. Glycated human hemoglobin 
( $H b A 1 c)$ : functional characteristics and molecular modeling studies. Biophys Chem. 1998;72(3):323-35.

78. Padilla DJ, McDonough P, Behnke BJ, Kano Y, Hageman KS, Musch TI, Poole DC. Effects of Type II diabetes on capillary hemodynamics in skeletal muscle. Am J Physiol Heart Circ Physiol. 2006;291(5):H2439-44.

79. Barclay JK. A delivery-independent blood flow effect on skeletal muscle fatigue. J Appl Physiol. 1986;61(3):1084-90.

80. Kahn JK, Zola B, Juni JE, Vinik Al. Radionuclide assessment of left ventricular diastolic filling in diabetes mellitus with and without cardiac autonomic neuropathy. J Am Coll Cardiol. 1986;7(6):1303-9.

81. Keller DM, Fadel PJ, Ogoh S, Brothers RM, Hawkins M, Olivencia-Yurvati A, Raven PB. Carotid baroreflex control of leg vasculature in exercising and non-exercising skeletal muscle in humans. J Physiol. 2004;561(Pt 1):283-93.

82. Hogikyan RV, Galecki AT, Halter JB, Supiano MA. Heightened norepinephrine-mediated vasoconstriction in type 2 diabetes. Metabolism. 1999;48(12):1536-41.

83. O'Connor E, Kiely C, O'Shea D, Green S, Egana M. Similar level of impairment in exercise performance and oxygen uptake kinetics in middleaged men and women with type 2 diabetes. Am J Physiol Regul Integr Comp Physiol. 2012;303(1):R70-6.

84. Wilkerson DP, Poole DC, Jones AM, Fulford J, Mawson DM, Ball Cl, Shore AC. Older Type 2 diabetic males do not exhibit abnormal pulmonary oxygen uptake and muscle oxygen utilization dynamics during submaximal cycling exercise. Am J Physiol-Regulatory Integrat Comparat Physiol. 2011;300(3):R685-92.

85. Verrotti A, Prezioso G, Scattoni R, Chiarelli F. Autonomic neuropathy in diabetes mellitus. Front Endocrinol. 2014;5:205.

86. Pop-Busui R, Evans GW, Gerstein HC, Fonseca V, Fleg JL, Hoogwerf BJ, Genuth S, Grimm RH, Corson MA, Prineas R, et al. Effects of cardiac autonomic dysfunction on mortality risk in the Action to Control Cardiovascular Risk in Diabetes (ACCORD) trial. Diabetes Care. 2010;33(7):1578-84

87. Group AC, Patel A, MacMahon S, Chalmers J, Neal B, Billot L, Woodward M, Marre M, Cooper M, Glasziou P, et al. Intensive blood glucose control and vascular outcomes in patients with type 2 diabetes. N Engl J Med. 2008;358(24):2560-72.

88. Duckworth W, Abraira C, Moritz T, Reda D, Emanuele N, Reaven PD, Zieve FJ, Marks J, Davis SN, Hayward R, et al. Glucose control and vascular complications in veterans with type 2 diabetes. N Engl I Med. 2009;360(2):129-39.

89. Pecanha T, Silva-Junior ND, Forjaz CL. Heart rate recovery: autonomic determinants, methods of assessment and association with mortality and cardiovascular diseases. Clin Physiol Funct Imaging. 2014;34(5):327-39.

90. Endo A, Kinugawa T, Ogino K, Kato M, Hamada T, Osaki S, Igawa O, Hisatome I. Cardiac and plasma catecholamine responses to exercise in patients with type 2 diabetes: prognostic implications for cardiaccerebrovascular events. Am J Med Sci. 2000;320(1):24-30.

91. Keytsman C, Dendale P, Hansen D. Chronotropic Incompetence During Exercise in Type 2 Diabetes: aetiology, Assessment Methodology, Prognostic Impact and Therapy. Sports Med. 2015;45(7):985-95.

92. Hansen D, Dendale P. Modifiable predictors of chronotropic incompetence in male patients with type 2 diabetes. J Cardiopulm Rehabil Prev. 2014;34(3):202-7.

93. Izawa K, Tanabe K, Omiya K, Yamada S, Yokoyama Y, Ishiguro T, Yagi M, Hirano Y, Kasahara Y, Osada N, et al. Impaired chronotropic response to exercise in acute myocardial infarction patients with type 2 diabetes mellitus. Jpn Heart J. 2003;44(2):187-99.

94. Gao M, Chen W, Gong ZK, Han L, Zhang L. Correlation between chronotropic incompetence and metabolic equivalents in patients with type 2 diabetes mellitus and concomitant metabolic syndrome. Panminerva Med. 2015;57(3):115-9.

95. Ho PM, Maddox TM, Ross C, Rumsfeld JS, Magid DJ. Impaired chronotropic response to exercise stress testing in patients with diabetes predicts future cardiovascular events. Diabetes Care. 2008:31(8):1531-3.

96. Smanio PEP, Carvalho AC, Tebexreni AS, Thom A, Rodrigues F, Meneghelo R, Mastrocolla L, Alves A, Piegas LS, de Paola AA. Coronary artery disease in asymptomatic type-2 diabetic women. A comparative study between exercise test, cardiopulmonary exercise test, and dipyridamole myocardial perfusion scintigraphy in the identification of ischemia. Arquivos Brasileiros De Cardiologia. 2007:89(5):290-7.

97. Zafrir B, Azencot M, Dobrecky-Mery I, Lewis BS, Flugelman MY, Halon DA. Resting heart rate and measures of effort-related cardiac autonomic dysfunction predict cardiovascular events in asymptomatic type 2 diabetes. Eur J Prev Cardiol. 2016;23(12):1298-306.

98. Curtis JM, Horton ES, Bahnson J, Gregg EW, Jakicic JM, Regensteiner JG, Ribisl PM, Soberman JE, Stewart KJ, Espeland MA, et al. Prevalence and predictors of abnormal cardiovascular responses to exercise testing among individuals with type 2 diabetes: the Look AHEAD (Action for Health in Diabetes) study. Diabetes Care. 2010;33(4):901-7.

99. Cheng YJ, Lauer MS, Earnest CP, Church TS, Kampert JB, Gibbons LW, Blair SN. Heart rate recovery following maximal exercise testing as a predictor of cardiovascular disease and all-cause mortality in men with diabetes. Diabetes Care. 2003;26(7):2052-7.

100. Chacko KM, Bauer TA, Dale RA, Dixon JA, Schrier RW, Estacio RO. Heart rate recovery predicts mortality and cardiovascular events in patients with type 2 diabetes. Med Sci Sports Exerc. 2008;40(2):288-95.

101. Cole CR, Blackstone EH, Pashkow FJ, Snader CE, Lauer MS. Heart-rate recovery immediately after exercise as a predictor of mortality. $N$ Engl J Med. 1999;341(18):1351-7.

102. Jin L, Min G, Wei C, Min H, Jie Z. Exercise training on chronotropic response and exercise capacity in patients with type 2 diabetes mellitus. Exp Ther Med. 2017;13(3):899-904.

103. Longhurst JC, Tjen ALSC, Fu LW. Cardiac sympathetic afferent activation provoked by myocardial ischemia and reperfusion. Mechanisms and reflexes. Ann N Y Acad Sci. 2001;940:74-95.

104. Zhang L, Xiong XQ, Fan ZD, Gan XB, Gao XY, Zhu GQ. Involvement of enhanced cardiac sympathetic afferent reflex in sympathetic activation in early stage of diabetes. J Appl Physiol. 2012;113(1):47-55.

105. Young JL, Pendergast DR, Steinbach J. Oxygen transport and peripheral microcirculation in long-term diabetes. Proc Soc Exp Biol Med. 1991;196(1):61-8

106. Puente-Maestu L, Palange P, Casaburi R, Laveneziana P, Maltais F, Neder $J A$, O'Donnell DE, Onorati P, Porszasz J, Rabinovich R, et al. Use of exercise testing in the evaluation of interventional efficacy: an official ERS statement. Eur Respir J. 2016;47(2):429-60.

107. Tantucci C, Scionti L, Bottini P, Dottorini ML, Puxeddu E, Casucci G, Sorbini CA. Influence of autonomic neuropathy of different severities on the hypercapnic drive to breathing in diabetic patients. Chest. 1997;112(1):145-53.

108. Whipp BJ, Ward SA, Wasserman K. Ventilatory responses to exercise and their control in man. Am Rev Respir Dis. 1984;129(2 Pt 2):S17-20.

109. Tantucci C, Bottini P, Fiorani C, Dottorini ML, Santeusanio F, Provinciali L, Sorbini CA, Casucci G. Cerebrovascular reactivity and hypercapnic respiratory drive in diabetic autonomic neuropathy. J Appl Physiol. 2001;90(3):889-96.

110. Pitocco D, Fuso L, Conte EG, Zaccardi F, Condoluci C, Scavone G, Incalzi RA, Ghirlanda G. The diabetic lung-a new target organ? Rev Diabet Stud. 2012;9(1):23-35.

111. Kemps H, Krankel N, Dorr M, Moholdt T, Wilhelm M, Paneni F, Serratosa L, Ekker Solberg E, Hansen D, Halle M, et al. Exercise training for patients with type 2 diabetes and cardiovascular disease: What to pursue and how to do it. A Position Paper of the European Association of Preventive Cardiology (EAPC). Eur J Prev Cardiol. 2019;26(7):709-27.

112. Sullivan PW, Morrato EH, Ghushchyan V, Wyatt HR, Hill JO. Obesity, inactivity, and the prevalence of diabetes and diabetes-related cardiovascular comorbidities in the U.S., 2000-2002. Diabetes Care. 2005;28(7):1599-603.

113. Amadid H, Johansen NB, Bjerregaard AL, Brage S, Faerch K, Lauritzen T, Witte DR, Sandbaek A, Jorgensen ME, Vistisen D. The role of physical activity in the development of first cardiovascular disease event: a tree-structured survival analysis of the Danish ADDITION-PRO cohort. Cardiovasc Diabetol. 2018;17(1):126

114. Castaneda C, Layne JE, Munoz-Orians L, Gordon PL, Walsmith J, Foldvari M, Roubenoff R, Tucker KL, Nelson ME. A randomized controlled trial of resistance exercise training to improve glycemic control in older adults with type 2 diabetes. Diabetes Care. 2002;25(12):2335-41.

115. Ibanez J, Izquierdo M, Arguelles I, Forga L, Larrion JL, Garcia-Unciti M, Idoate F, Gorostiaga EM. Twice-weekly progressive resistance training 
decreases abdominal fat and improves insulin sensitivity in older men with type 2 diabetes. Diabetes Care. 2005;28(3):662-7.

116. Holloszy JO. Exercise-induced increase in muscle insulin sensitivity. J Appl Physiol. 2005;99(1):338-43.

117. Balducci S, Zanuso S, Nicolucci A, Fernando F, Cavallo S, Cardelli P, Fallucca S, Alessi E, Letizia C, Jimenez A, et al. Anti-inflammatory effect of exercise training in subjects with type 2 diabetes and the metabolic syndrome is dependent on exercise modalities and independent of weight loss. Nutr Metab Cardiovasc Dis. 2010;20(8):608-17.

118. Qiu S, Cai X, Yin H, Sun Z, Zugel M, Steinacker JM, Schumann U. Exercise training and endothelial function in patients with type 2 diabetes: a meta-analysis. Cardiovasc Diabetol. 2018;17(1):64

119. Magalhaes JP, Melo X, Correia IR, Ribeiro RT, Raposo J, Dores H, Bicho M, Sardinha LB. Effects of combined training with different intensities on vascular health in patients with type 2 diabetes: a 1-year randomized controlled trial. Cardiovasc Diabetol. 2019;18(1):34.

120. Anand V, Garg S, Garg J, Bano S, Pritzker M. Impact of exercise training on cardiac function among patients with type 2 diabetes: a SYSTEMATIC REVIEW AND META-ANALYSIS. J Cardiopulm Rehabil Prev. 2018:38(6):358-65.

121. Pandey A, Patel KV, Bahnson JL, Gaussoin SA, Martin CK, Balasubramanyam A, Johnson KC, McGuire DK, Bertoni AG, Kitzman D, et al. Association of intensive lifestyle intervention, fitness, and body mass index with risk of heart failure in overweight or obese adults with type 2 diabetes mellitus: an analysis from the look AHEAD trial. Circulation. 2020;141(16):1295-306.

122. Ur Rehman SS, Karimi H, Gillani SA, Ahmad S. Effects of supervised structured aerobic exercise training programme on level of Exertion, dyspnoea, VO2 max and Body Mass Index in patients with type 2 diabetes mellitus. J Pak Med Assoc. 2017;67(11):1670-3.

123. Pandey A, Swift DL, McGuire DK, Ayers CR, Neeland IJ, Blair SN Johannsen N, Earnest CP, Berry JD, Church TS. Metabolic effects of exercise training among fitness-nonresponsive patients with type 2 diabetes: the HART-D Study. Diabetes Care. 2015;38(8):1494-501.

124. Brandenburg SL, Reusch JE, Bauer TA, Jeffers BW, Hiatt WR, Regensteiner $J G$. Effects of exercise training on oxygen uptake kinetic responses in women with type 2 diabetes. Diabetes Care. 1999;22(10):1640-6.

125. Oktay AA, Lavie CJ, Kokkinos PF, Parto P, Pandey A, Ventura HO. The interaction of cardiorespiratory fitness with obesity and the obesity paradox in cardiovascular disease. Prog Cardiovasc Dis. 2017;60(1):30-44.

126. Bouchard C, An P, Rice T, Skinner JS, Wilmore JH, Gagnon J, Perusse L, Leon AS, Rao DC. Familial aggregation of VO(2max) response to exercise training: results from the HERITAGE Family Study. J Appl Physiol. 1999;87(3):1003-8.

127. Banks AZ, Mentz RJ, Stebbins A, Mikus CR, Schulte PJ, Fleg JL, Cooper LS, Leifer ES, Badenhop DT, Keteyian SJ, et al. Response to exercise training and outcomes in patients with heart failure and diabetes mellitus: insights from the HF-ACTION Trial. J Card Fail. 2016;22(7):485-91.

128. Church TS, Blair SN, Cocreham S, Johannsen N, Johnson W, Kramer K, Mikus CR, Myers V, Nauta M, Rodarte RQ, et al. Effects of aerobic and resistance training on hemoglobin A1c levels in patients with type 2 diabetes: a randomized controlled trial. JAMA. 2010;304(20):2253-62.

129. Stoa EM, Meling S, Nyhus LK, Glenn S, Mangerud KM, Helgerud J, Bratland-Sanda S, Storen O. High-intensity aerobic interval training improves aerobic fitness and $\mathrm{HbA} 1 \mathrm{c}$ among persons diagnosed with type 2 diabetes. Eur J Appl Physiol. 2017;117(3):455-67.

130. De Nardi AT, Tolves T, Lenzi TL, Signori LU, Silva A. High-intensity interval training versus continuous training on physiological and metabolic variables in prediabetes and type 2 diabetes: a meta-analysis. Diabetes Res Clin Pract. 2018;137:149-59.

131. Magalhaes JP, Judice PB, Ribeiro R, Andrade R, Raposo J, Dores H, Bicho $M$, Sardinha LB. Effectiveness of high-intensity interval training combined with resistance training versus continuous moderate-intensity training combined with resistance training in patients with type 2 diabetes: a one-year randomized controlled trial. Diabetes Obes Metab. 2019;21(3):550-9.

132. Hernandez-Alvarez MI, Thabit H, Burns N, Shah S, Brema I, Hatunic M, Finucane F, Liesa M, Chiellini C, Naon D, et al. Subjects with early-onset type 2 diabetes show defective activation of the skeletal muscle PGC-1 \{alpha\}/Mitofusin-2 regulatory pathway in response to physical activity. Diabetes Care. 2010;33(3):645-51.

133. Srisawat K, Shepherd SO, Lisboa PJ, Burniston JG. A systematic review and meta-analysis of proteomics literature on the response of human skeletal muscle to obesity/type 2 diabetes Mellitus (T2DM) versus exercise training. Proteomes. 2017;5(4):30.

134. Hetherington-Rauth M, Magalhaes JP, Judice PB, Melo X, Sardinha LB. Vascular improvements in individuals with type 2 diabetes following a 1 year randomised controlled exercise intervention, irrespective of changes in cardiorespiratory fitness. Diabetologia. 2020;63(4):722-32.

135. Konopka AR, Laurin JL, Schoenberg HM, Reid JJ, Castor WM, Wolff CA, Musci RV, Safairad OD, Linden MA, Biela LM, et al. Metformin inhibits mitochondrial adaptations to aerobic exercise training in older adults. Aging Cell. 2019;18(1):e12880.

136. Ostergard T, Andersen JL, Nyholm B, Lund S, Nair KS, Saltin B, Schmitz O. Impact of exercise training on insulin sensitivity, physical fitness, and muscle oxidative capacity in first-degree relatives of type 2 diabetic patients. Am J Physiol Endocrinol Metab. 2006;290(5):E998-1005.

137. Scalzo RL, Peltonen GL, Binns SE, Klochak AL, Szallar SE, Wood LM, Larson DG, Luckasen GJ, Irwin D, Schroeder T, et al. The effects of sympathetic inhibition on metabolic and cardiopulmonary responses to exercise in hypoxic conditions. Wilderness Environ Med. 2015;26(4):520-4.

138. Nolen-Doerr E, Crick K, Saha C, de Groot M, Pillay Y, Shubrook JH, Donley D, Hornsby WG Jr. Six-minute walk test as a predictive measure of exercise capacity in adults with type 2 diabetes. Cardiopulm Phys Ther J. 2018;29(3):124-9.

139. Pedersen LR, Olsen RH, Anholm C, Astrup A, Eugen-Olsen J, Fenger M, Simonsen L, Walzem RL, Haugaard SB, Prescott E. Effects of 1 year of exercise training versus combined exercise training and weight loss on body composition, low-grade inflammation and lipids in overweight patients with coronary artery disease: a randomized trial. Cardiovasc Diabetol. 2019;18(1):127.

\section{Publisher's Note}

Springer Nature remains neutral with regard to jurisdictional claims in published maps and institutional affiliations.

\footnotetext{
Ready to submit your research? Choose BMC and benefit from:

- fast, convenient online submission

- thorough peer review by experienced researchers in your field

- rapid publication on acceptance

- support for research data, including large and complex data types

- gold Open Access which fosters wider collaboration and increased citations

- maximum visibility for your research: over 100M website views per year
}

At BMC, research is always in progress.

Learn more biomedcentral.com/submissions 